UNIVERSIDADE DE BRASÍLIA

FACULDADE DE TECNOLOGIA

DEPARTAMENTO DE ENGENHARIA ELÉTRICA

\title{
ANÁLISE DE CONTINGÊNCIAS EM SISTEMAS ELÉTRICOS DE POTÊNCIA
}

\author{
HENRIQUE SCHAEFFER BATISTA
}

ORIENTADOR: IVAN MARQUES DE TOLEDO CAMARGO

MONOGRAFIA DE GRADUAÇÃO EM ENGENHARIA ELÉTRICA 
UNIVERSIDADE DE BRASÍLIA

FACULDADE DE TECNOLOGIA

DEPARTAMENTO DE ENGENHARIA ELÉTRICA

\section{ANÁLISE DE CONTINGÊNCIAS EM SISTEMAS ELÉTRICOS DE POTÊNCIA}

HENRIQUE SCHAEFFER BATISTA

MONOGRAFIA SUBMETIDA AO DEPARTAMENTO DE ENGENHARIA ELÉTRICA DA FACULDADE DE TECNOLOGIA DA UNIVERSIDADE DE BRASÍLIA COMO PARTE DOS REQUISITOS NECESSÁRIOS PARA A OBTENÇÃO DO GRAU DE ENGENHEIRO ELETRICISTA.

APROVADA POR:

Prof. Ivan Marques de Toledo Camargo, Dr. (ENE-UnB) (Orientador)

Prof. Francisco Damasceno Freitas, Dr. (ENE-UnB)

(Examinador Interno)

João Odilon Freitas e Silva, Dr. (CNOS/CORS-NCO - ONS)

(Examinador Externo)

BRASÍLIA-DF, 27 DE JUNHO DE 2008. 


\section{FICHA CATALOGRÁFICA}

\section{BATISTA, HENRIQUE SCHAEFFER}

Análise de Contingências em Sistemas Elétricos de Potência [Distrito Federal] 2008. vii, 48p., (ENE/FT/UnB, Engenheiro Eletricista, 2008). Monografia de Graduação Universidade de Brasília. Faculdade de Tecnologia.

Departamento de Engenharia Elétrica.

1. Contingência

3. Inequações

I. ENE/FT/UnB
2. Carregamento

4. Sistema Elétrico

II. Título (série)

\section{REFERÊNCIA BIBLIOGRÁFICA}

BATISTA, H. S. (2008). Análise de Contingências em Sistemas Elétricos de Potência. Monografia de Graduação, Publicação ENE 01/2008, Departamento de Engenharia Elétrica, Universidade de Brasília, Brasília, DF, 48p.

\section{CESSÃO DE DIREITOS}

AUTOR: Henrique Schaeffer Batista.

TÍTULO: Análise de Contingências em Sistemas Elétricos de Potência.

GRAU: Engenheiro Eletricista ANO: 2008

É concedida à Universidade de Brasília permissão para reproduzir cópias desta monografia de graduação e para emprestar ou vender tais cópias somente para propósitos acadêmicos e científicos. O autor reserva outros direitos de publicação e nenhuma parte dessa monografia de graduação pode ser reproduzida sem autorização por escrito do autor.

Henrique Schaeffer Batista 
DEDICATÓRIA

Ao meu filho Renato.

Aos meus Pais Adílio e Sandra.

E minha Irmã Raquel. 


\section{AGRADECIMENTOS}

Agradeço a Deus por ter me dado o dom da vida e por ter me fortalecido nos momentos de dificuldade, possibilitando o fechamento da minha jornada na graduação em Engenharia Elétrica.

Agradeço ao apoio de todos os meus familiares que sempre estiveram presentes em minha vida, me incentivando a prosseguir em busca dos meus objetivos.

Agradeço aos colegas do ONS que sempre estiveram dispostos a me ajudar na elaboração dessa monografia e agregaram valores a minha formação profissional.

Agradeço ao Professor Dr. Ivan Marques de Toledo Camargo pela confiança em mim depositada, pela paciência e cordialidade durante a minha vida acadêmica.

Agradeço aos amigos feitos durante o período de graduação que estiveram ao meu lado e sempre pude contar para todas as horas.

Agradeço aos professores do Departamento de Engenharia Elétrica pela disposição em transmitir os conhecimentos necessários para me tornar um profissional capacitado. 


\title{
RESUMO
}

\section{ANÁLISE DE CONTINGÊNCIAS EM SISTEMAS ELÉTRICOS DE POTÊNCIA}

\author{
Autor: Henrique Schaeffer Batista. \\ Orientador: Ivan Marques de Toledo Camargo. \\ Palavras-chave: contingência, carregamento, inequações, sistema elétrico. \\ Brasília, 27 de junho de 2008.
}

O presente trabalho trata de análises de contingências em sistemas elétricos de potência. Durante este estado, os carregamentos nos equipamentos do sistema devem estar abaixo do limite nomina, evitando assim a atuação de proteções, as quais poderiam levar a uma reação em cadeia e dessa forma ocasionar um colapso.

Para essas análises é necessário que se conheça o sistema elétrico, sabendo como se comportam, por exemplo, os fluxos de potência em equipamentos de transmissão, as tensões e a freqüência do sistema. Nos primeiros capítulos é mostrada uma visão qualitativa do comportamento de sistemas elétricos de potência, visando alcançar o entendimento necessário para efetuar as análises.

As contingências em sistemas elétricos são muito comuns, e normalmente estão relacionadas a desligamentos de equipamentos para manutenção (intervenções). No caso do Sistema Interligado Nacional, deve-se atender a um critério chamado N-1, no qual o sistema deve suportar contingências simples sem prejuízo ao atendimento de consumidores e aos equipamentos da rede. Para isso, se for constatada a possibilidade de contingência, os fluxos de potência dos equipamentos envolvidos na mesma devem ser controlados em tempo real de forma, que caso a contingência ocorra, não haja sobrecarga de qualquer equipamento da rede.

Os fluxos nos equipamentos que poderão estar envolvidos em uma contingência são monitorados levando-se em conta leis matemáticas baseadas em inequações de carregamento. As inequações podem ser de dois ou três elementos e serão mostradas as metodologias usadas para a elaboração destas inequações.

Por fim, neste trabalho, é desenvolvida uma nova metodologia de elaboração das inequações de três elementos a qual é tão eficiente quanto a atual, ficando essa metodologia como uma alternativa para avaliara o controle de carregamento de equipamentos. 


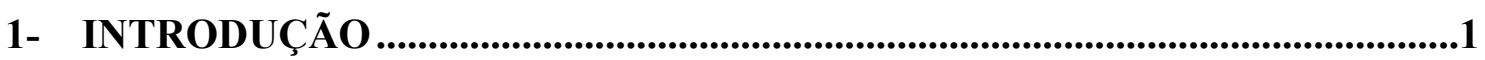

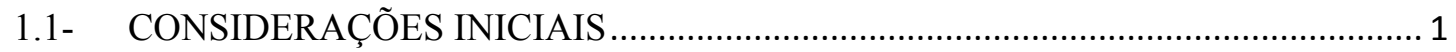

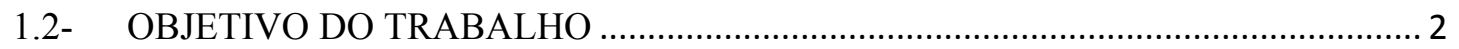

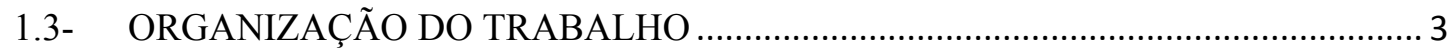

2- VISÃO GERAL DE SISTEMAS ELÉTRICOS DE POTÊNCIA ..........................4

2.1- O EQUILÍBRIO ENTRE GERAÇÃO E CARGA..................................................... 4

2.2- A CONEXÃO ENTRE GERAÇÃO E CARGA …………………………………...

3- OPERAÇÃO DE SISTEMAS ELÉTRICOS............................................................7

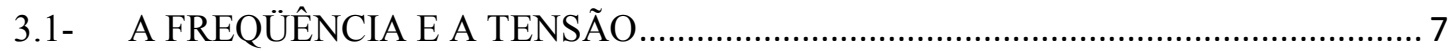

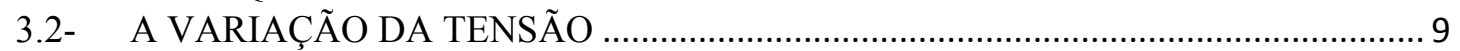

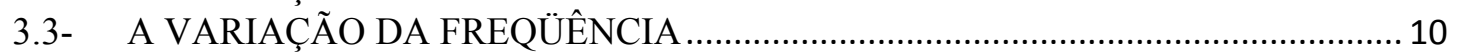

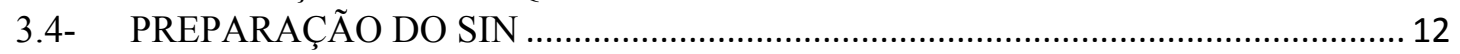

4- ANÁLISE DE CONTINGÊNCIAS EM SISTEMAS ELÉTRICOS ...................14

4.1- INEQUAÇÃO DE DOIS ELEMENTOS ................................................................. 16

4.1.1 - Elaboração de Inequações de Dois Elementos....................................................................16

4.1.2- Cálculo de Fatores de Realocação de Geração ..................................................................19

4.1.3- Exemplo Real de Inequação de dois Elementos. ....................................................................20

4.2- INEQUAÇÃO DE TRÊS ELEMENTOS ……….................................................. 23

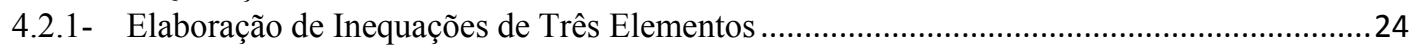

4.2.2- Cálculo de Fatores de Realocação de Geração …………………………………………….....26

4.2.3- Exemplo Real de Inequações de Três Elementos .................................................................26

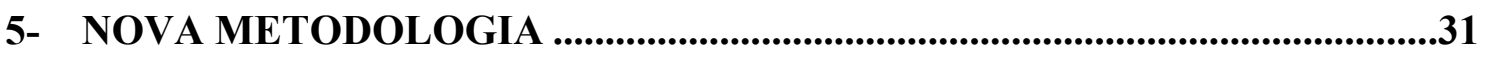

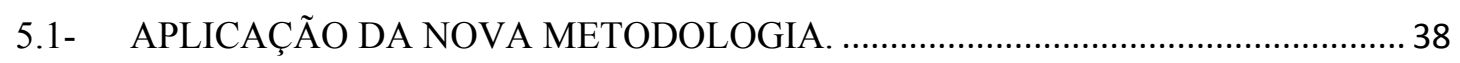

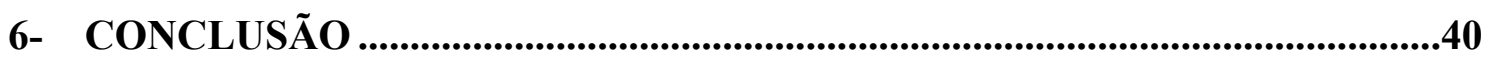

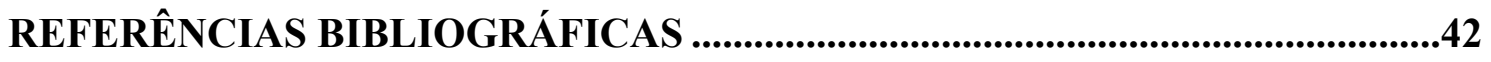

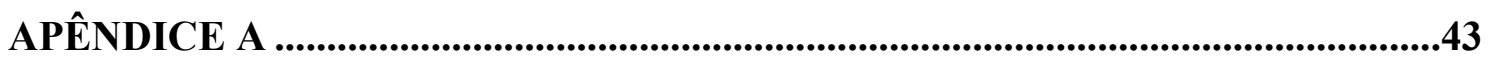




\section{LISTA DE FIGURAS}

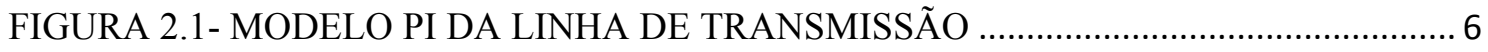

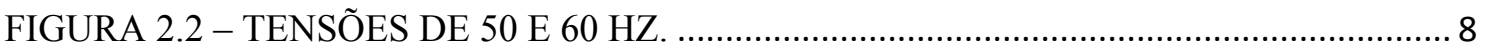

FIGURA 4.1 - CONFIGURAÇÃO DO SIN EM TORNO DA SE TIJUCO PRETO.................. 20

FIGURA 4.2 - CONFIGURAÇÃO DO BARRAMENTO DA SE CAMAÇARI II..................... 27

FIGURA 4.3 - MODELAGEM DA SE CAMAÇARI II PARA POSSIBILITAR A

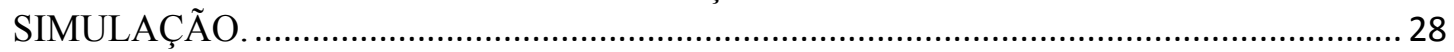

FIGURA 4.4 - APLICAÇÃO DA $1^{\mathrm{a}}$ LEI DE KIRCHHOFF. ...................................................... 28

FIGURA 5.1 - FLUXO DE POTÊNCIA NO TRANSFORMADOR 2 DA SE CAMAÇARI II

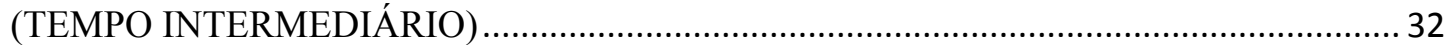

FIGURA 5.2 - ZOOM DO PERÍODO TRANSITÓRIO DO FLUXO DE POTÊNCIA DO TRANSFORMADOR 2 DA SE CAMAÇARI II (TEMPO INTERMEDIÁRIO)................... 32 FIGURA 5.4 - FLUXO DE POTÊNCIA NO TRANSFORMADOR 2 DA SE CAMAÇARI II

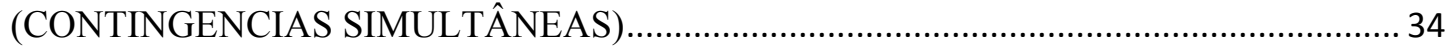




\section{1- INTRODUÇÃO}

\section{1- CONSIDERAÇÕES INICIAIS}

Sistemas Elétricos de Potência apresentam uma operação complicada, pois para garantir padrões de qualidade, diversas fases de programação e execução de eventos relacionados aos sistemas estão em constante interação.

Buscar sempre o estado da arte é um dos grandes motivadores deste trabalho. O foco principal que será abordado neste trabalho é voltado para a análise de sobrecarga de equipamentos por meio da análise de contingências. As contingências basicamente são eventos em equipamentos do sistema que deixam de operar por atuação de proteções devido a algum problema. Contingências acontecem a todo momento em sistemas elétricos de potência e não é interessante que a saída de equipamentos cause problemas aos outros que continuam em operação.

As análises de contingências são importantes para se avaliar o sistema em um ponto de operação e para saber se é possível minimizar o impacto das contingências sobre os outros equipamentos. Os sistemas elétricos de potência normalmente trabalham com certa "folga", para que caso ocorra uma contingências se evite falhas em cadeia, provocando o desabastecimento de energia.

Garantir os requisitos estabelecidos para a operação de sistemas elétricos não é uma tarefa simples. Há toda uma metodologia para isso, que os consumidores nem imaginam a complexidade. Por exemplo, eles não fazem idéia de como é difícil manter a tensão das instalações de sua residência em um valor aproximadamente constante.

Para entender e prever como contingências vão influenciar nos parâmetros do sistema e em outros equipamentos é necessário ter pelo menos uma idéia de como o sistema é constituído - entendendo seu comportamento, e principalmente como ele é operado - onde se visa manter requisitos previamente estabelecidos (tensão e freqüência) e a integridade dos equipamentos. 


\section{2- OBJETIVO DO TRABALHO}

O presente trabalho tem por objetivo entender como é o comportamento de sistemas elétricos de potência e minimizar os problemas de carregamento dos equipamentos inseridos no sistema dado uma ou mais contingências. Isto é alcançado por meio de uma metodologia que será apresentada mais a frente. Em especial, o estudo terá como base o desempenho do Sistema Interligado Nacional (SIN), dando-se ênfase à "rede de transmissão" (acima de $138 \mathrm{kV}$ ).

As possíveis contingências devem ser analisadas de modo que, caso venham ocorrer, sejam evitados problemas nos equipamentos remanescentes. Neste trabalho, foca-se principalmente avaliação da sobrecarga dos equipamentos que continuam em operação. Para isso, é apresentada uma metodologia que permite prever (aproximadamente) o carregamento dos equipamentos no momento de póscontingência. A metodologia citada baseia-se no estudo de inequações de monitoramento, as quais fazem parte da operação do SIN.

Essas análises de contingências, na maioria dos casos, estão relacionadas a pedidos de intervenções (manutenções) no SIN. Normalmente essas manutenções submetem o sistema a configurações que podem ser prejudiciais a equipamentos, em caso de contingências.

As inequações são artifícios matemáticos utilizados para monitorar os equipamentos remanescentes e assim evitar que esses entrem em sobrecarga após uma ou mais contingências. Assim é possível prever, antecipadamente, qual será o carregamento dos equipamentos em questão. Ressalta-se que existe uma pequena probabilidade de que a contingência possa acontecer. Mas, de qualquer forma, o sistema deve estar preparado para suportá-la.

Por fim, estuda-se a possibilidade de desenvolver uma nova metodologia para a elaboração das inequações que envolva mais de uma contingência. Fica a critério do analista da intervenção o uso da nova alternativa ou o método tradicional. 


\section{3- ORGANIZAÇÃO DO TRABALHO}

O Capítulo 2 apresenta uma visão qualitativa de como um sistema elétrico de potência é constituído.

O Capítulo 3 mostra também de forma qualitativa quais são as dificuldades encontradas na operação de sistemas elétricos de potência, bem como saná-las, descrevendo os requisitos exigidos para o correto funcionamento do sistema.

O Capítulo 4 trata das metodologias usadas para a análise de contingências e para a elaboração de inequações de dois e três elementos, juntamente com exemplos reais verificados no SIN.

O Capítulo 5 desenvolve a nova metodologia como alternativa para análises de contingências, considerando a inequação de três elementos. Também mostra-se a aplicação da nova metodologia em um exemplo abordado no capítulo 4.

No Capítulo 6 apresenta-se a conclusão sobre o trabalho. 


\section{2- VISÃO GERAL DE SISTEMAS ELÉTRICOS DE POTÊNCIA}

Neste capítulo é dada uma visão qualitativa de como um sistema elétrico de potência é constituído. Começando pela parte do equilíbrio entre geração e carga, onde são estudadas as relações entre essas grandezas. Por fim é considerada a forma como é feita a conexão entre geração e carga.

\section{1- O EQUILÍBRIO ENTRE GERAÇÃO E CARGA}

Até os dias atuais não existem meios de armazenar energia na forma elétrica. Mesmo em baterias, a energia é armazenada por reações químicas. Portanto, toda energia elétrica, gerada pelas usinas de um determinado sistema, deve ser consumida pelas cargas deste sistema. Ou seja, a potência gerada em um instante deve ser consumida no mesmo instante. Esse processo é chamado de equilíbrio entre geração e carga. O mesmo pode ser interpretado como a soma entre as potências gerada e consumida. Para que o sistema funcione corretamente o equilíbrio entre geração e carga deve ser zero a todo momento.

Como a potência consumida em qualquer sistema elétrico tem comportamento aleatório, a potência gerada está sempre seguindo o sinal de potência consumida para poder, assim, permitir o fechamento do equilíbrio ente geração e carga.

Por que a carga é aleatória? Essa resposta é simples: porque a todo o momento estão sendo ligados e desligados equipamentos à rede elétrica. Imaginando a seguinte situação: em uma casa, quando um indivíduo entra em seu quarto e liga a lâmpada, o sistema percebe imediatamente o aumento de carga, quando ele sai do quarto e desliga a lâmpada novamente o sistema sente a diminuição da carga. Quando essas ações foram tomadas, pelo indivíduo, não houve uma programação, ele não precisou avisar a concessionária de energia em qual hora a lâmpada iria ser ligada e em qual hora iria desligá-la. Agora, considerando milhões de pessoas e milhões de equipamentos, com milhares de potências diferentes, interagindo a todo o momento com o sistema elétrico tem-se uma noção de como a carga é aleatória.

Apesar de ser aleatória, a carga pode ser prevista de acordo com o comportamento da população à qual ela está associada. Por exemplo, no Brasil, durante a madrugada a carga é mais baixa que no horário comercial, que é mais baixa que no período da noite. Isso porque na madrugada a maior parte da população está dormindo. 
Durante o horário comercial, as fábricas, escritórios, etc. estão em atividade. Já à noite a população costuma tomar banho ligando chuveiros elétricos - um vilão do consumo de potência. Tomando-se como base esses argumentos, definem-se os patamares tradicionais de carga como carga leve, média e pesada, durante as 24 horas do dia.

\section{2- A CONEXÃO ENTRE GERAÇÃO E CARGA}

A forma como a potência é transferida das usinas aos centros de carga (consumidores) é por meio de equipamentos - linhas de transmissão e transformadores - que constituem as redes de transmissão e distribuição. No Brasil há níveis de tensão de transmissão que se estende de $138 \mathrm{kV}$ até $765 \mathrm{kV}$. Os níveis de distribuição vão de $110 \mathrm{~V}$ até $69 \mathrm{kV}$. Cada equipamento tem um limite máximo de potência que pode transmitir. Esse limite deve ser respeitado a todo o momento.

Os fluxos nos equipamentos de transmissão são definidos pela potência das cargas às quais estão "alimentando", pelas usinas mais influentes (normalmente as eletricamente mais próximas) e pela topologia da rede. A potência que atravessa essa rede tem duas componentes, a potência ativa - mais sensível à abertura angular entres as barras adjacentes ao equipamento de transmissão - e a reativa - mais sensível à diferença de potencial entre as barras adjacentes ao equipamento de transmissão.

Assim, de posse de uma previsão de carga e de geração para um horizonte de 10 ou 20 anos, o projeto das redes, tanto de transmissão quanto de distribuição, é feito para que os limites dos equipamentos sejam respeitados. Ou seja, a topologia da rede é concebida para garantir que os carregamentos dos equipamentos fiquem razoavelmente abaixo do nominal.

Quando todos os equipamentos das redes estão em operação, diz-se que a rede está na configuração de rede completa. Por outro lado se há algum equipamento fora de operação, diz-se que a rede está na configuração de rede alterada.

Os fluxos nos equipamentos geralmente ficam abaixo do limite nominal. Isto possibilita que em situações de saída de equipamentos, seja para manutenções ou por atuações de proteções, não provoquem sobrecarga nos equipamentos remanescentes. Entretanto em algumas regiões as redes podem não garantir o respeito a esses limites. 
Muitas das vezes, por falta de reforços à medida que a carga evolui ao passar dos anos. Nesses casos, são avaliados outros recursos, os quais serão destacados nos próximos capítulos.

No presente texto será enfatizada a rede de transmissão, mas sem desconsiderar a rede de distribuição.

Toda linha de transmissão tem parâmetros distribuídos ao longo de seu comprimento (resistência, indutância e capacitância). Em série, têm-se associadas uma resistência e uma reatância indutiva que são inerentes ao material do qual a linha é constituída. Entretanto, para que a linha possa ser modelada, a resistência e a indutância são representadas de forma concentrada. Outro efeito a ser considerado para longas linhas de transmissão é o efeito capacitivo. Nesse caso, os níveis de tensão são elevados o suficiente para que haja armazenamento de energia reativa entre a linha de transmissão e a terra. Fazendo uma analogia com um capacitor de placas paralelas, ou seja, duas placas separadas por um dielétrico, onde uma placa seria a linha e a outra seria a imagem da linha na terra - teoria das imagens estudada em eletromagnetismo estando separadas por um dielétrico que é o ar. Para linhas longas a capacitância é maior porque a área das "placas" também é maior. Observa-se que essa capacitância está em paralelo com a resistência e indutância acima descritas. Para a adequada modelagem da linha, novamente, faz-se uma concentração deste parâmetro constituindo, assim, o modelo PI da linha, conforme Figura 2.1.

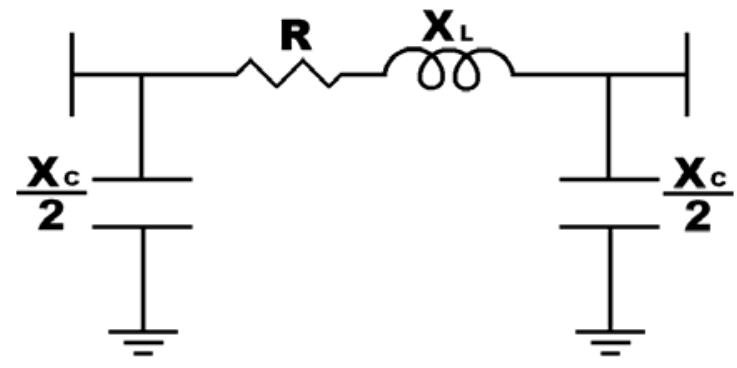

FIGURA 2.1- MODELO PI DA LINHA DE TRANSMISSÃO.

No caso dos transformadores, a modelagem é simplesmente uma reatância em série com uma resistência. Como a reatância no caso do transformador é muito maior que a resistência pode-se desprezá-la e considerar o modelo como uma simples reatância. 


\section{3- OPERAÇÃO DE SISTEMAS ELÉTRICOS}

São abordados neste capítulo os princípios da operação de sistemas elétricos, dando maior ênfase para o Sistema Interligado Nacional (SIN), o qual é operado pelo Operador Nacional do Sistema Elétrico (ONS).

Sabe-se que existem alguns parâmetros que nos sistemas elétricos deveriam permanecer constantes, tais como tensão e freqüência. Essas características são essenciais a fim de se manter os padrões de fabricação dos equipamentos conectados à rede e para, principalmente, permitir a interligação de usinas e subsistemas. Esses requisitos serão explicados qualitativamente nas próximas seções. Na seção 3.1 é explicado porque a tensão e a freqüência devem estar em patamares praticamente constantes e nas seções 3.2 e 3.3 são explicados os fatores que afetam a variação da tensão e da freqüência de sistemas elétricos de potência.

Há também no caso da operação do SIN, um critério de confiabilidade do sistema. Todo o sistema deve ser capaz de suportar determinadas contingências sem que haja prejuízo do atendimento de energia elétrica aos consumidores. Esse critério é abordado na seção 3.4 .

\section{1- A FREQÜÊNCIA E A TENSÃO}

Imaginando duas unidades geradoras conectadas ao mesmo barramento. Suponha que uma unidade tem capacidade de gerar potência à freqüência de $60 \mathrm{~Hz}$ e a outra unidade pode gerar potência à freqüência de $50 \mathrm{~Hz}$. Em determinado momento haverá diferença de potencial entre as mesmas fases conectadas (Figura 2.2). Dependendo dessa diferença de potencial surgirão correntes entre os geradores da ordem de correntes de curto-circuito, além das ressonâncias associadas, pois hora uma fornece, hora recebe potência. Nesse caso podem atuar proteções desconectando os geradores. Fazendo a extrapolação para sistemas interligados pode haver o desligamento da interligação ocorrendo o desequilíbrio entre carga e geração, sendo necessário o corte de carga em uma região e de geração na outra. Logo, deve-se definir um valor padrão para a freqüência de oscilação do sistema. 
A freqüência pode ser diferente dependendo do país. Por exemplo, no Brasil o SIN opera a $60 \mathrm{~Hz}$, já no Paraguai o sistema opera a $50 \mathrm{~Hz}$.

Entretanto, na prática, a freqüência de oscilação de um sistema não é constante, ela está sempre variando em torno do valor determinado. A explicação para este fenômeno está descrita na seção 3.3.

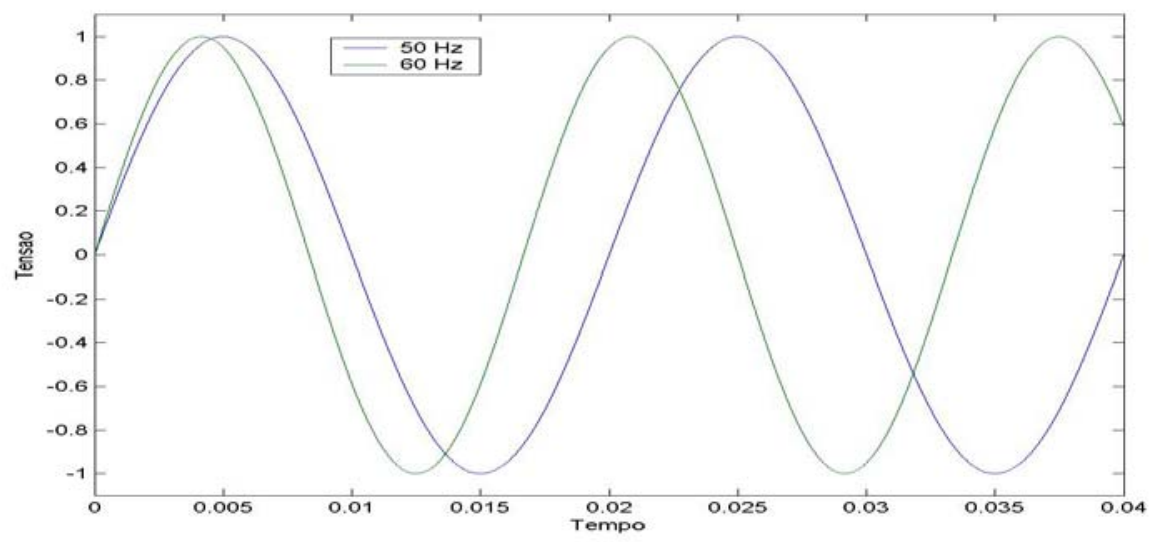

FIGURA 2.2 - TENSÕES DE 50 E 60 HZ.

Com relação à tensão entregue aos consumidores, quando ela encontra-se muito baixa, os equipamentos podem não funcionar corretamente ou mesmo ser danificados. Considerando que alguns equipamentos podem ser modelados como potência (S) constante, havendo tensão baixa os equipamentos exigem mais corrente, podendo essa corrente superar o limite nominal dos memsmos provocando a queima (Equação (3.1)). Um exemplo de equipamento que pode ser modelado como potência constante são motores funcionando em fábricas. Quando a tensão está muito alta pode também levar à queima de equipamentos, sendo os mesmos modelados como impedância $(Z)$ constante. Nesse caso, aumentando-se a tensão, a corrente também aumenta, podendo ultrapassar o limite do equipamento (Equação (3.2)). Um exemplo de equipamento que pode ser modelado como impedância constante são os equipamentos eletrônicos. Assim fica evidente que a tensão deve permanecer em um patamar definido.

$$
\begin{aligned}
& S=V \times I \\
& Z=\frac{V}{I}
\end{aligned}
$$


Na grande maioria dos sistemas elétricos a tensão deve ser mantida em 1 p.u. Entretanto, da mesma forma que acontece com a freqüência, a tensão também varia em torno do valor especificado. Esse fenômeno é explicado na seção 3.2.

A maior parte das análises feitas em um sistema elétrico considera a tensão e a freqüência constantes. Porém, essas grandezas só são constantes na teoria. Na prática tensão e freqüência estão variando a todo o momento, dentro de patamares estabelecidos e em torno dos valores 1 p.u. e $60 \mathrm{~Hz}$, respectivamente.

\section{2- A VARIAÇÃO DA TENSÃO}

Sabe-se que os elementos indutivos consomem potência reativa e que os capacitivos fornecem potência reativa para o sistema ao qual estão conectados. Como foi mostrada anteriormente, a carga e a geração estão conectadas por meio de uma malha composta por linhas de transmissão e distribuição, as quais possuem parâmetros indutivos e capacitivos.

Ao longo do dia, a carga vai variando de acordo com os patamares de carga. No patamar de carga pesada, a potência requerida pela carga é muito alta, sendo necessário um maior fluxo de potência atravessando a rede de transmissão. Assim a parte indutiva das linhas irá consumir mais potência reativa da geração e consumir também toda a potência reativa fornecida pelo efeito capacitivo das linhas. Logo será entregue menos potência reativa aos consumidores (carga). No patamar de carga leve, a potência requerida é muito baixa, o que provoca um baixo fluxo de potência atravessando a rede de transmissão. Assim o consumo de potência reativa na rede é menor que a potência reativa fornecida pelo efeito capacitivo das linhas. Logo há mais potência reativa disponível às cargas.

Como é de conhecimento de todo engenheiro eletricista, a potência reativa e a tensão estão intimamente relacionadas. Ou seja, diminuindo a potência reativa, disponível em determinada barra do sistema, a tensão nesta barra cai. O contrário também é válido. Para que esse problema seja resolvido é necessário aumentar ou diminuir a quantidade de potência reativa disponível para o sistema. Para modificar essa oferta de potência reativa pode-se utilizar equipamentos como compensador síncrono (motor síncrono que funciona sub ou sobre-excitado, consumindo ou fornecendo 
potência reativa, respectivamente), compensadores estáticos (bancos de capacitores e reatores automaticamente chaveados), reatores e capacitores manobráveis. Pode-se também alterar a geração de potência reativa nas unidades geradoras e, em caso de carga leve, sendo o último recurso disponível, abrir circuitos caso existam circuitos paralelos.

A operação de qualquer sistema visa manter a tensão dentro dos patamares especificados utilizando esses recursos de controle de tensão. Na operação do SIN os limites de tensão dependem de qual nível de tensão está em questão, pois quanto maior o nível maior é a margem de regulação. Por exemplo, em $500 \mathrm{kV}$ a tensão pode variar entre 0,9 e 1,1 p.u.. Já em $138 \mathrm{kV}$ a tensão deve ficar entre 0,95 e 1,05 p.u..

\section{3- A VARIAÇÃO DA FREQÜÊNCIA}

Considera-se agora a freqüência do sistema. Quando o há um desequilíbrio entre carga e geração com a variação da carga, os geradores devem responder a essa variação. Entretanto, para que os mesmos respondam, são necessários alguns décimos de segundo ou mais.

Os geradores sentem essa variação de carga pela variação da freqüência de oscilação do sistema. Esta freqüência está intimamente relacionada com a velocidade de rotação do eixo da turbina. Sempre que a freqüência atingir o patamar inferior ou superior, o controle de velocidade é sensibilizado.

Esse fenômeno ocorre da seguinte forma: quando há uma variação da carga os geradores não respondem imediatamente, pois é necessária a abertura ou fechamento dos distribuidores das turbinas para que seja entregue mais ou menos potência ativa nos eixos das máquinas e a mesma seja transferida às cargas. Para que os distribuidores sejam abertos ou fechados há associação de constantes de tempo mecânicas que são muito maiores que as constantes de tempo elétricas. Ou seja, a potência ativa da carga varia mais rapidamente que a potência ativa gerada. Assim, para pequenas variações de carga o equilíbrio entre carga e geração é alcançado - pelo princípio da conservação da energia - através da variação da energia cinética, Ec, de rotação das massas girantes dos conjuntos turbinas e geradores. Como o momento de inércia, J, dos eixos é constante durante o processo, o que vai variar é a velocidade de rotação dos eixos, $\omega$. Com isso, 
também varia a freqüência do sistema, f. Portanto, quando a carga aumenta, parte da energia cinética é transformada em elétrica e com isso a freqüência diminui. Quando a carga diminui, parte da energia elétrica é transformada em energia cinética aumentando a freqüência (Equações (3.3) e (3.4)). Quando a freqüência estiver perto dos limites superior ou inferior, os controles de velocidade atuam abrindo ou fechando os distribuidores das turbinas.

$$
\begin{aligned}
& E c=\frac{J \omega^{2}}{2} \\
& f=\frac{\omega}{2 \pi}
\end{aligned}
$$

A variação da freqüência pode trazer os problemas citados anteriormente, além de outros. Por exemplo, a potência elétrica está associada à freqüência. Logo, uma variação muito grande da freqüência danificaria os equipamentos conectados ao sistema. Os problemas de estabilidade também podem ocorrer, fazendo com que o haja um desequilíbrio maior entre carga e geração, acarretando uma reação em cadeia, de desligamentos, a qual pode chegar a um "Blackout".

A variação da freqüência deve ser controlada em um intervalo não muito grande, para evitar os problemas mencionados. No caso do SIN, a freqüência pode variar entre 59,5 e $60,5 \mathrm{~Hz}$.

Para controlar a freqüência do sistema são usados os controles de velocidade dos geradores, como exposto acima. Entretanto esse controle é usado para fazer um ajuste "grosso" no sistema. Há a necessidade de se fazer um controle mais refinado, pois a freqüência deve variar em um intervalo muito pequeno. No SIN há outro controle chamado Controle Automático de Geração (CAG) o qual é instalado em usinas estratégicas para fazer o ajuste "fino" da freqüência do sistema. A finalidade desse tipo de controle é alterar a geração de usinas com maior potência instalada. Nessas usinas, normalmente há uma maior faixa de regulação para a potência que pode ser despachada. O CAG também é usado para controlar as oscilações de interligações entre regiões, quando uma região está exportando grande quantidade de potência para outra. 


\section{4- PREPARAÇÃO DO SIN}

Na operação do SIN há um critério de suma importância. Todo o sistema deve estar preparado para a perda (contingência) simples de qualquer equipamento - seja de transmissão ou geração - sem que os consumidores e os demais equipamentos sofram danos e prejudique o atendimento às cargas. Esse critério deve ser atendido tanto em rede completa quanto em rede alterada e leva o nome de critério N-1. As contingências são muito comuns no dia-a-dia da operação. Elas estão sempre ocorrendo por diversos motivos, tais como fenômenos da natureza, desgaste de equipamentos, atuação indevida de proteções, falha de equipamentos, entre outros.

Em determinadas regiões esse critério é atendido simplesmente pelo fato da topologia da rede ser bem robusta. Entretanto há regiões onde a topologia é "fraca" e não suporta uma contingência simples - mesmo em rede completa - e o critério N-1 é atendido usando-se alguns artifícios, os quais serão abordados nos próximos capítulos.

Dada uma contingência o sistema deve ser preparado o quanto antes para que o critério N-1 seja atendido novamente. Por exemplo, em um ramo com quatro circuitos idênticos, em paralelo, com um circuito desligado para manutenção, o sistema deve suportar a perda de outro circuito. Se, por um acaso, ocorrer a contingência citada, os operadores de tempo real devem preparar o sistema para suportar uma segunda contingência.

A operação do SIN, e de qualquer sistema elétrico, convive diariamente com pedidos de intervenções (que basicamente são manutenções em equipamentos). Essas podem ser com desligamento ou não (trabalho em linha viva), podem ser programadas ou de urgência (tem que ser executadas, pois coloca em risco o sistema, equipamentos ou pessoas) ou de emergência (o equipamento já está desligado por causa de uma contingência).

$\mathrm{Na}$ fase de programação ou em tempo real, intervenções solicitadas devem ser analisadas de forma que a rede não sofra nenhum prejuízo com a nova topologia. Caso seja concluído que não é o momento adequado para sua execução, o analista pode tentar reprogramar para um período favorável ou simplesmente negar a intervenção, caso o agente que fez o pedido não concorde com a reprogramação. 
Em casos de contingências onde todas as medidas foram tomadas e não se consegue, por exemplo, sanar uma sobrecarga em um equipamento após a contingência de outro, as proteções de sobre-corrente atuarão, fazendo com que o equipamento em sobrecarga seja desligado. Dependendo da topologia da rede, poderá haver corte de carga ou geração. E nesse caso, o critério N-1 não foi atendido.

Como um balanço final do capítulo, a operação de sistemas elétricos visa o melhor funcionamento do sistema, buscando manter a qualidade da energia elétrica entregue aos consumidores. Essa qualidade é atingida quando há um certo equilíbrio entre a geração e a carga, a tensão e a freqüência de oscilação do sistema estão dentro dos limites e em torno do valor especificado, os equipamentos estão funcionando dentro dos limites de carregamento, e, em caso de contingências, não ocorrer prejuízo do atendimento às cargas e dos equipamentos da rede. 


\section{4- ANÁLISE DE CONTINGÊNCIAS EM SISTEMAS ELÉTRICOS}

Como foi comentado anteriormente, na operação do SIN o critério N-1 deve ser atendido a todo o momento. Foi visto que em determinadas regiões ou em determinadas situações não se consegue atendê-lo, simplesmente devido à condição da topologia da rede. Portanto, para que esse critério possa ser atendido foram criados artifícios onde é possível garantir o seu atendimento.

Basicamente, busca-se prever os carregamentos de equipamentos após uma contingência. E para que não haja sobrecarga, os fluxos nesses equipamentos são controlados enquanto houver risco de ocorrer a contingência. No SIN, esse artifício é realizado por meio da modelagem de uma inequação que deve ser monitorada durante a operação em tempo real.

Há casos em que elabora-se inequações para atender o critério N-1 de forma permanente, pois mesmo com a rede completa, determinada região do sistema não suporta a perda de algum equipamento, podendo haver sobrecarga em outros equipamentos. Essas inequações, no caso do SIN, são elaboradas, por exemplo, pelas áreas de estudos do ONS.

Uma segunda possibilidade, inequações são elaboradas pelas áreas de programação ou de tempo real (caso de urgência ou emergência). Essas normalmente são programadas para atender o critério N-1 de forma provisória. Possivelmente, as inequações estão associadas a um desligamento para manutenção de equipamento. Assim a rede fica alterada e há a necessidade de monitoramento dos carregamentos.

O principal objetivo de se monitorar as inequações é evitar que o fluxo final $\left(F 1_{\mathrm{f}}\right)$ de determinado equipamento supere seu limite nominal de emergência, caso ocorra alguma contingência. Logo, esse fluxo deve atender a:

$$
F 1_{f}<\text { Limite }
$$

Inequações deste tipo são implantadas na sala de controle do ONS e cadastradas em softwares de monitoramento do sistema, onde as informações em campo têm um atraso de no máximo 3 segundos em relação ao que é visualizado nos painéis da sala de controle. Quando há a violação de inequações cadastradas, um alarme visual é disparado para que o operador da região tome as medidas cabíveis, visando ao 
atendimento da inequação novamente e assim assegurar que não haverá sobrecarga nos equipamentos envolvidos, em caso de contingência.

A filosofia das inequações é saber qual é a influência, em termos de carregamento, que determinado equipamento exerce sobre o carregamento do outro. $\mathrm{Ou}$ seja, dada a contingência de um equipamento, qual será a influência de sua saída no carregamento de outro. Assim, as inequações baseiam-se na previsão do carregamento de equipamentos que ficaram em operação, na situação de pós-contingência. Essa previsão é feita por meio de artifício matemático, o qual usa o princípio da superposição considerando os equipamentos envolvidos na análise.

Há a possibilidade de uma contingência envolver mais de um desligamento. Por exemplo, considerando um curto-circuito em uma linha onde um dos disjuntores (que deveriam atuar) falha. Nessa situação, ocorrerá a atuação da proteção de retaguarda e com isso ocasiona uma segunda contingência. Essa segunda contingência pode agravar o carregamento dos equipamentos que ficarão em operação após a mesma. Além de falhas de equipamentos, alguns esquemas de proteção podem provocar essa segunda contingência.

A elaboração de inequações foi concebida a partir da formulação linearizada do fluxo de potência (fluxo DC), onde o fator de carregamento pela saída de um equipamento dependerá somente da configuração de rede. Entretanto, para o processo de fluxo de potência não-linear, essa metodologia pode ser considerada uma aproximação aceitável.

Sabe-se que para aplicar o princípio da superposição, o processo deve ser linear. Apesar do fluxo de potência resultar em uma operação não-linear, essa metodologia vem sendo usada com sucesso, pois ela não considera a linearidade para encontrar o novo ponto de operação do sistema em caso de contingência e sim uma estimativa deste ponto. Os pontos de operação são definidos em simulações nãolineares, usando os métodos numéricos tradicionais. Essa metodologia é uma aproximação que considera linear apenas o "caminho" pelo qual o sistema passou para chegar ao ponto de operação de pós-contingência. Este ponto é determinado por meio de simulações em aplicativos como o Anarede - Programa de Análise de Redes, programa de fluxo de potência oficial, utilizado para simulações no SIN. Ressalta-se que em problemas reais existem imprecisões associadas aos equipamentos de medições. 
Portanto, deve-se entender que sempre há um erro associado à metodologia, seja pela aproximação ou pela medição (em tempo real).

\section{1- INEQUAÇÃO DE DOIS ELEMENTOS}

Inicialmente para se elaborar uma inequação é necessário que se definam os equipamentos que estão sob risco de desligamento por causa de intervenções, por causa de fenômenos da natureza, ou simplesmente, por causa da topologia da rede. Devem-se observar quais são as contingências mais graves, pois normalmente, sendo controlados os carregamentos para essas contingências, os carregamentos para as contingências menos severas já estarão sob controle. Na maioria das vezes, são monitoradas as inequações do pior caso de contingência.

De posse das contingências devem-se verificar quais equipamentos podem sofrer sobrecarga, caso elas venham a ocorrer. Definidos os equipamentos, deve-se ajustar o caso base do sistema (dados de modelagem) a ser simulado para que a configuração de rede esteja próxima à real. Ou seja, modificar os fluxos das linhas quando estes estiverem muito discrepantes dos observados em tempo real, ajustando a geração ou carga, alterar quando necessário a tensão nas barras por meio de injeção de potência reativa e desligar equipamentos que estejam fora de operação por manutenção ou outros motivos. Normalmente, os casos base do ONS apresentam a configuração de rede completa (nenhum equipamento desligado), a menos que esteja programada uma intervenção com desligamento e com tempo de execução muito longo que indisponibilize o equipamento.

\subsection{1- Elaboração de Inequações de Dois Elementos}

A partir do caso base ajustado, verificam-se os fluxos de potência ativa nos equipamentos envolvidos na análise. Posteriormente, simula-se a contingência e anotam-se os fluxos de potência ativa nos equipamentos em análise.

Pode-se montar uma tabela conforme a Tabela 4.1, para ajudar na elaboração da inequação, relacionada à contingência do equipamento 2 . 
Tabela 4.1 - Fluxos de Potência Ativa nos Equipamentos Envolvidos na Análise de Contingência.

\begin{tabular}{|c|c|c|}
\hline Equipamento & Fluxo no Momento Inicial $\left(\mathbf{T}_{\mathbf{i}}\right)$ & Fluxo no Momento Final $\left(\mathbf{T}_{\mathbf{f}}\right)$ \\
\hline 1 & $\mathrm{~F} 1_{\mathrm{i}}$ & $\mathrm{F} 1_{\mathrm{f}}$ \\
\hline 2 & $\mathrm{~F} 2_{\mathrm{i}}$ & 0 \\
\hline
\end{tabular}

Nesse momento já se sabe qual é o carregamento simulado do equipamento 1, após verificada a contingência do equipamento 2. Esse procedimento já é uma boa aproximação do que aconteceria em um sistema real. Entretanto, a estimativa do carregamento do equipamento 1 deve ser feita a partir dos fluxos iniciais, pois as inequações serão monitoradas em tempo real. Não adiantaria simplesmente controlar o fluxo após a contingência, pois o equipamento ficaria submetido à sobrecarga até que fossem tomadas as medidas cabíveis. Portanto, os fluxos devem ser monitorados antes da contingência, para que, caso a mesma ocorra, o equipamento remanescente não entre em sobrecarga. Assim, é necessária uma associação das grandezas iniciais com o carregamento final do equipamento 1 .

Essa associação é conseguida a partir da equação:

$$
F 1_{f}=F 1_{i}+K \times F 2_{i}
$$

$\mathrm{O}$ fator $\mathrm{K}$ é definido como a influência sobre o equipamento 1, caso ocorra a perda do equipamento 2 . Ou seja, é verificada a seguinte relação:

$$
K=\frac{F 1_{f}-F 1_{i}}{F 2_{i}}
$$

Quando se faz a simulação, as tensões das barras adjacentes ao equipamento analisado na configuração de rede alterada (pós-contingência) devem ser observadas. Pois como se sabe, o limite dos equipamentos é de corrente e não de potência. Entretanto, como a tensão da rede deveria ser constante, pode-se fazer a analogia de corrente com potência aparente. Mas sabe-se que a tensão pode variar dentro de um intervalo. Assim, depois da contingência, a tensão pode ficar muito perto do limite inferior aceitável ou até violá-lo. Supondo que o equipamento que esteja com o carregamento sendo monitorado "enxergue" a carga modelada como potência constante. Assim, ocorrerá uma corrente elevada provocando sobrecarga no mesmo, apesar de não violar o limite de potência (em MVA). 
Quando esse fato acontecer, pode-se fazer uma nova estimativa do limite de potência do equipamento, fazendo uma proporção do limite de potência com o quadrado da tensão no momento de pós-contingência, considerando que o limite fornecido pelo fabricante do equipamento está relacionado à tensão de 1 p.u..

Pode-se também recomendar que enquanto estiver acontecendo a intervenção, quando for o caso, as tensões das barras adjacentes devem estar próximas aos limites superiores. Para este objetivo, manobras como a desconexão reatores manobráveis de barra, conexões de capacitores manobráveis de barras, ajuste de geração de reativos das usinas e de compensadores síncronos e estáticos mais influentes, devem ser buscados.

Por que só é considerada a potência ativa e não a potência aparente no carregamento de equipamentos? Os sistemas de transmissão operam normalmente em tensões acima de 1 p.u. o que provoca uma diminuição da corrente que atravessa os equipamentos de transmissão (novamente veja Equação (3.1)), já que a maioria das cargas são modeladas como potência constante. Também, nas simulações feitas verificou-se que o fluxo de potência reativa muda muito pouco com as contingências. Isto porque, mesmo aumentando a impedância (contingência de um dos caminhos de escoamento de geração) na conexão das usinas às cargas, a impedância equivalente dos circuitos remanescentes, normalmente, continua baixa, o que implica em baixo consumo de potência reativa na rede de transmissão em configuração alterada. Logo, a "oferta" de potência reativa às cargas diminui pouco e as tensões das barras adjacentes variam muito pouco. Como já foi descrito, os valores podem continuar acima ou próximos de 1 p.u. o que acarreta em correntes menores que as correntes nominais dos equipamentos.

Outro parâmetro que pode ser levado em consideração sobre a questão levantada acima é que o objetivo de sistemas elétricos de potência é de transmitir potência ativa já que a demanda de potência reativa pode ser suprida por meio de fontes (banco de capacitores e compensadores estáticos e síncronos) que são instaladas mais próximas aos centros de carga. A instalação dessas fontes faz com que a tensão nas barras de carga sejam superiores a 1 p.u., pois a oferta de potência reativa nessas barras é alta. Sabe-se que o fluxo de potência reativa está relacionado com a diferença de tensão entre os barramentos, por isso tenta-se manter as tensões de todo o sistema acima de 1 p.u. para que o fluxo de potência reativa seja minimizado e o fluxo de potência 
ativa, considerando os limites dos equipamentos de transmissão, seja otimizado. Assim, fica evidente que a maior parcela da potência aparente é constituída por potência ativa.

Levando-se em conta o que foi exposto acima, fica evidente que não há prejuízos em se considerar somente a potência ativa como fator limitante no carregamento de equipamentos da rede de transmissão.

\subsection{2- Cálculo de Fatores de Realocação de Geração}

Não basta simplesmente montar a inequação, pois em tempo real pode ocorrer sua violação e em caso de acontecer a contingência a sobrecarga não será evitada. Para que os operadores possam sanar esse eventual problema, é necessário que os fluxos nos equipamentos envolvidos na inequação sejam controlados. Assim, a medida que pode ser tomada é o redespacho de determinadas usinas mais influentes, já que não se tem o controle da carga, como foi mostrado anteriormente.

Mas fica a questão: quais usinas devem ser reprogramadas e de quanto deve ser a reprogramação de geração? Os operadores devem ter uma lista com as usinas que possuem maior sensibilidade na inequação. Normalmente, as usinas escolhidas são as que ficam eletricamente mais próximas da região onde a análise está sendo feita e/ou as usinas que têm maior margem de regulação.

Para saber quanto uma usina influencia na inequação, deve-se primeiramente saber o quanto essa usina impacta em cada uma das parcelas (equipamentos sob análise) da inequação. Existe, em muitos programas de fluxo de potência, um comando para fazer a análise de sensibilidade de determinados equipamentos à variação de geração de determinadas usinas. Este é o caso do Anarede. Entretanto, se o analista não tiver acesso ou não conhecer o recurso citado, pode-se fazer a análise manualmente. Basta fazer uma variação de geração em usinas eletricamente próximas ao local analisado e ver qual foi o percentual de variação nos fluxos dos equipamentos sob análise. Lembrando que se deve fazer essa análise em uma usina por vez. Um exemplo genérico: quando se aumenta $100 \mathrm{MW}$ na usina $\mathrm{A}$, o fluxo no equipamento 1 aumenta $40 \mathrm{MW}$ e no equipamento 2 aumenta $25 \mathrm{MW}$, assim a sensibilidade do equipamento 1 à variação de geração na usina A é de $40 \%$ e do equipamento 2 é de $25 \%$. 
Feita a análise de sensibilidade para os equipamentos envolvidos, onde S1 é a sensibilidade do equipamento 1 em relação à usina $\mathrm{A}, \mathrm{S} 2$ é a sensibilidade do equipamento 2 em relação à mesma usina. $\mathrm{O}$ fator final de influência $\left(\mathrm{S}_{\mathrm{f}}\right)$ da usina $\mathrm{A}$ sobre a inequação deve ser o seguinte:

$$
S_{f}=S 1+K \times S 2
$$

Onde o fator K é o mesmo calculado anteriormente na Equação (4.3).

A partir da Equação (4.4), é montada uma lista das usinas com seus respectivos fatores de influência sobre a inequação monitorada. Seguindo uma ordem de prioridade de maior impacto sobre a inequação.

Em tempo real, caso haja violação da inequação, algumas dessas usinas têm seus despachos reprogramados para que a inequação seja atendida e dessa forma seja evitada a sobrecarga em caso de contingência dos equipamentos envolvidos na inequação. $\mathrm{Na}$ hora de decidir qual usina será reprogramada, além de observar a ordem de impacto sobre a inequação, também é observada a prioridade energética de cada uma das usinas relacionadas na lista acima citada (despacho por ordem de mérito).

\subsection{3- Exemplo Real de Inequação de dois Elementos.}

No mês de outubro de 2007, foi requerida uma intervenção para o transformador 3, 765/500 kV da subestação de Tijuco Preto. Essa intervenção necessitava do equipamento desligado. A configuração dos transformadores da subestação está mostrada na Figura 4.1.

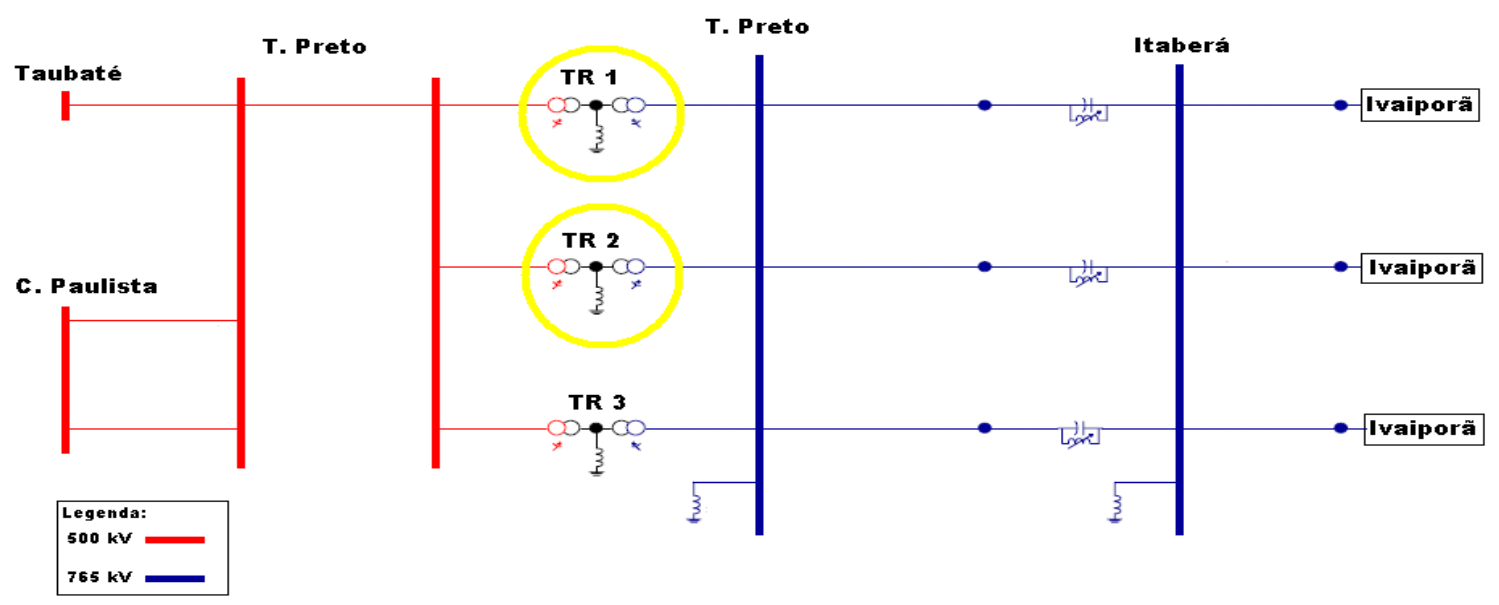

FIGURA 4.1 - CONFIGURAÇÃO DO SIN EM TORNO DA SE TIJUCO PRETO. 
O SIN é preparado para operar somente com os transformadores 1 e 2 sem prejuízo dos equipamentos remanescentes. Entretanto o SIN não está preparado para a contingência de um transformador, na configuração de rede alterada. Dependendo dos fluxos nesses equipamentos, a contingência de um deles pode causar sobrecarga no remanescente e, com isso, pode ocorrer a atuação da proteção, fazendo perder toda a transformação de 765/500 kV da Subestação (SE) Tijuco Preto. É importante salientar que a SE Tijuco Preto é um dos pontos de escoamento da geração de Itaipu. Existe um esquema especial de proteção para essa transformação. Caso ocorra sobrecarga, em qualquer um dos transformadores há corte de geração em Itaipu, o que pode prejudicar o equilíbrio entre carga e geração do sistema na região Sudeste, podendo levar a perdas de estabilidade. Portanto é evidente que se deve controlar o carregamento da transformação 765/500 kV da SE Tijuco Preto a fim de evitar que ocorra a sobrecarga e conseqüentemente a atuação do esquema.

Para essa análise foi usado o programa Anarede, e inicialmente foi ajustado o caso base (de carga média) de forma que o transformador 3 estivesse desligado. Nesse momento foram verificados os fluxos nos transformadores 1 e 2. Em um segundo momento, foi simulado o desligamento do transformador 1 - poderia ser $\mathrm{o}$ transformador 2 que não faria diferença, pois os dois transformadores são idênticos - e foi verificado o fluxo no transformador 2. Todos esses dados estão na Tabela 4.2. Nos diagramas do Apêndice A pode-se observar os fluxos de potência nos equipamentos modelados no Anarede - da região onde se encontra a subestação Tijuco Preto (nos momentos de pré e pós-contingência).

Tabela 4.2: Análise da Contingência em Tijuco Preto.

\begin{tabular}{|c|c|c|}
\hline Equipamento & $\mathbf{T}_{\mathbf{i}}$ & $\mathbf{T}_{\mathbf{f}}$ \\
\hline Transformador $2\left(\mathrm{~T}_{2}\right)$ & $1066,8 \mathrm{MW}$ & $1852,1 \mathrm{MW}$ \\
\hline Transformador 1 $\left(\mathrm{T}_{1}\right)$ & $1049,2 \mathrm{MW}$ & $0 \mathrm{MW}$ \\
\hline
\end{tabular}

Nesse momento é calculado o fator K da inequação conforme mostrado abaixo:

$$
K=\frac{1852,1-1066,8}{1049,2}=0,7485
$$

O limite de operação de cada transformador $765 / 500 \mathrm{kV}$ da SE Tijuco Preto é de 1650 MVA. Como as tensões nas barras adjacentes não variaram muito, como era 
esperado, esse limite não precisa ser alterado. Assim a inequação fica da seguinte forma:

$$
F\left(T_{2}\right)+0,7485 \times F\left(T_{1}\right)<1650 \mathrm{MW}
$$

Onde:

$\mathrm{F}\left(\mathrm{T}_{2}\right)$ é o fluxo em MW no transformador 2, medido do lado de alta tensão.

$\mathrm{F}\left(\mathrm{T}_{1}\right)$ é o fluxo em MW no transformador 1, medido do lado de alta tensão.

$1650 \mathrm{MW}$ é o limite do transformador 1.

Nessa etapa é necessário fazer a análise de sensibilidade para cada um dos equipamentos e montar a sensibilidade da Inequação (4.6) à variação de geração de cada usina escolhida. Para isso, usa-se a metodologia explicada anteriormente na seção 4.1.2.

As usinas escolhidas foram Itaipu $60 \mathrm{~Hz}$, Luiz Carlos Barreto, Jaguara e Furnas. As três últimas usinas são usinas conectadas eletricamente perto da SE Tijuco Preto, do lado de $500 \mathrm{kV}$. Já Itaipu foi escolhida porque a transformação da SE Tijuco Preto escoa parte de sua geração, como já citado.

As sensibilidades dos transformadores 1 e 2 à variação da geração em cada uma das usinas estão explicitadas na Tabela 4.3, juntamente com o cálculo da sensibilidade final da Inequação (4.6), calculada por meio da Equação (4.4).

Tabela 4.3: Lista de Usinas e fatores de Sensibilidade para Redespacho em Caso de Violação da Inequação 4.6.

\begin{tabular}{|c|c|c|c|c|}
\hline Usina & TR. 2 & TR. 1 & Equação 4.4 & $\mathbf{S}_{\mathbf{f}}$ \\
\hline Itaipu 60 Hz & $6,6 \%$ & $6,5 \%$ & $6,6+0,7485 \times 6,5$ & $11,7 \%$ \\
\hline L. C. Barreto & $-5,4 \%$ & $-5,3 \%$ & $-5,4+0,7485 \times(-5,3)$ & $-9,37 \%$ \\
\hline Jaguara & $-5,4 \%$ & $-5,4 \%$ & $-5,4+0,7485 \times(-5,4)$ & $-9,44 \%$ \\
\hline Furnas & $-6,5 \%$ & $-6,4 \%$ & $-6,5+0,7485 \times(-6,4)$ & $-11,29 \%$ \\
\hline
\end{tabular}

Nesse caso observa-se que para algumas usinas a sensibilidade foi negativa, o que significa que um aumento de geração nessas usinas faz com que os carregamentos dos equipamentos envolvidos na inequação diminuam. 


\section{2- INEQUAÇÃO DE TRÊS ELEMENTOS}

Existe a possibilidade de uma contingência provocar outra, retirando de operação outro equipamento. Quando ocorre isso, os carregamentos dos equipamentos remanescentes podem ser severamente aumentados. Esse tipo de contingência não ocorre simultaneamente, pois é necessário que ocorra a primeira contingência, para que, essa sim, sensibilize uma segunda proteção que irá atuar depois. Normalmente, o intervalo de tempo entre a primeira contingência e a segunda é de aproximadamente 100 milissegundos (ms).

Assim, é necessário, em determinadas situações que podem ocorrer esse fenômeno, considerar a contingência de dois elementos da rede de transmissão. Logo, deve-se avaliar os carregamentos dos equipamentos remanescentes com a configuração de rede alterada após a primeira contingência e após a segunda contingência. Ou seja, considera-se um tempo intermediário $\left(\mathrm{T}_{\mathrm{m}}\right)$. Normalmente essa situação de contingência ocorre por atuação de esquemas de proteção ou falhas de equipamentos de proteção (por exemplo, falha de disjuntor).

Há situações específicas, nas quais deve ser considerada tal tipo de contingências. Quando há evidências estatísticas de determinada contingência seguida de algumas conseqüências, tais como: instabilidade de potência, freqüência ou tensão em determinada região, interrupção de $25 \%$ da carga de um estado ou $30 \%$ da carga de uma região metropolitana ou $100 \mathrm{MW}$ de carga industrial, atuações de esquemas regionais de alívio de carga (ERAC), e por fim restrições de transferência de energia, pondo em risco o atendimento de uma região. Esses critérios são estabelecidos nos procedimentos de rede para a operação do SIN. Em outros sistemas os critérios para executar esse tipo de análise podem ser diferentes.

Para se fazer essa análise, devem ser consideradas as mesmas situações que as consideradas para inequações de dois elementos. Entretanto, agora considerando a saída de dois equipamentos relacionados a uma primeira contingência e respeitando a ordem cronológica em que ocorrem as contingências.

Identificadas as contingências, constatada a necessidade da inequação de três elementos e um dos critérios para tal análise esteja atendido, deve-se ajustar o caso base 
para uma situação mais próxima da real possível, conforme já citado. Lembrando que normalmente os casos base do ONS estão na configuração de rede completa.

\subsection{1- Elaboração de Inequações de Três Elementos}

Com o caso base devidamente ajustado, deve-se verificar os fluxos de potência ativa dos equipamentos envolvidos na análise. Posteriormente simula-se a primeira contingência e verificam-se os fluxos de potência ativa nos equipamentos envolvidos na análise. Por fim simula-se a segunda contingência e novamente verificam-se os fluxos de potência ativa nos equipamentos envolvidos na análise.

Para Inequações de três elementos é fortemente recomendado que se monte uma tabela como a Tabela 4.4, pois na etapa dos cálculos pode ocorrer alguma confusão, e a tabela será de grande utilidade.

Tabela 4.4 - Fluxos de Potência Ativa nos Equipamentos Envolvidos na Análise de Contingência.

\begin{tabular}{|c|c|c|c|}
\hline Equipamento & $\mathbf{T}_{\mathbf{i}}$ & $\mathbf{T}_{\mathbf{m}}$ & $\mathbf{T}_{\mathbf{f}}$ \\
\hline 1 & $\mathrm{~F} 1_{\mathrm{i}}$ & $\mathrm{F} 1_{\mathrm{m}}$ & $\mathrm{F} 1_{\mathrm{f}}$ \\
\hline 2 & $\mathrm{~F} 2_{\mathrm{i}}$ & 0 & 0 \\
\hline 3 & $\mathrm{~F} 3_{\mathrm{i}}$ & $\mathrm{F} 3_{\mathrm{m}}$ & 0 \\
\hline
\end{tabular}

Nesse momento já se sabe qual é o carregamento (simulado) do equipamento 1 após as contingências, o qual é uma excelente aproximação do que aconteceria no sistema real. Entretanto, como já foi explicado, as grandezas verificadas em tempo real são os fluxos iniciais e a partir deles é feita uma previsão do carregamento do equipamento 1 dadas as contingências. Como os fluxos verificados em tempo real estão constantemente variando, não se pode afirmar que o carregamento verificado na simulação será o que vai acontecer. Por isso, é necessário que se verifique qual é o impacto das contingências sobre o equipamento 1. Assim, segundo a metodologia das inequações de dois elementos, o fluxo final do equipamento 1 é dado por:

$$
F 1_{f}=F 1_{m}+K_{3} \times F 3_{m}
$$

$\mathrm{O}$ fator $\mathrm{K}_{3}$ é o fator de influência no equipamento 1 - no tempo final - em relação à perda do equipamento 3 - no tempo intermediário. Assim $\mathrm{K}_{3}$ é dado pela equação: 


$$
K_{3}=\frac{F 1_{f}-F 1_{m}}{F 3_{m}}
$$

Entretanto, a Equação (4.7) ainda está em função das grandezas relacionadas ao tempo intermediário. Logo, essas grandezas devem ser manipuladas para que fiquem em função dos tempos iniciais, viabilizando o monitoramento em tempo real.

Assim:

$$
\begin{aligned}
& F 1_{m}=F 1_{i}+K_{1} \times F 2_{i} \\
& F 3_{m}=F 3_{i}+K_{2} \times F 2_{i}
\end{aligned}
$$

Onde,

$$
\begin{aligned}
& K_{1}=\frac{F 1_{m}-F 1_{i}}{F 2_{i}} \\
& K_{2}=\frac{F 3_{m}-F 3_{i}}{F 2_{i}}
\end{aligned}
$$

Os fatores $\mathrm{K}_{1}$ e $\mathrm{K}_{2}$ são, respectivamente, os fatores de influência do equipamento 2 sobre os equipamentos 1 e 3 .

Fazendo a substituição das Equações (4.9) e (4.10) na Equação (4.7):

$$
\begin{aligned}
& F 1_{f}=F 1_{i}+K_{1} \times F 2_{i}+K_{3} \times\left(F 3_{i}+K_{2} \times F 2_{i}\right) \Rightarrow \\
& F 1_{f}=F 1_{i}+\left(K_{1}+K_{2} \times K_{3}\right) \times F 2_{i}+K_{3} \times F 3_{i}
\end{aligned}
$$

Assim, considerado a (4.1) fíca evidente a inequação de três elementos.

$$
F 1_{i}+\left(K_{1}+K_{2} \times K_{3}\right) \times F 2_{i}+K_{3} \times F 3_{i}<\text { Limite }
$$

Novamente, são observadas as tensões nas barras adjacentes ao equipamento 1, pelo mesmo motivo descrito para inequações de dois elementos, pois caso a tensão caia muito, deve-se reconsiderar o limite da Inequação (4.14), seguindo o que foi descrito anteriormente. 


\subsection{2- Cálculo de Fatores de Realocação de Geração}

Para inequações de três elementos também há a necessidade da confecção de uma lista de usinas, as quais têm influência sobre os carregamentos dos equipamentos sob análise. Para confeccionar essa lista é necessário realizar os estudos de sensibilidade de cada equipamento envolvido nas contingências consideradas (S1, S2 e S3) para a elaboração da inequação.

O cálculo dos fatores de realocação de geração, para controle dos fluxos que a inequação está relacionada (e assim garantir que não haverá sobrecarga nos equipamentos envolvidos), segue a mesma metodologia das inequações de dois elementos. Com uma pequena diferença: os fatores que vão multiplicar as sensibilidades dos equipamentos à geração de uma usina, são os mostrados na a seguir:

$$
S_{f}=S 1+\left(K_{1}+K_{2} \times K_{3}\right) \times S 2+K_{3} \times S 3
$$

Onde os fatores $\mathrm{K}_{1}, \mathrm{~K}_{2}$ e $\mathrm{K}_{3}$ são os mesmo calculados nas Equações (4.8), (4.11) e (4.12), respectivamente.

Nesse ponto a Equação (4.15) é usada para confeccionar uma lista de usinas que podem ser redespachadas em tempo real, caso haja violação da inequação em questão. Busca-se atender novamente a inequação, para evitar a sobrecarga dos equipamentos em caso de contingências.

\subsection{3- Exemplo Real de Inequações de Três Elementos}

No mês de novembro de 2007, foi requerida uma intervenção com desligamento para o disjuntor $15 \mathrm{~L} 5(500 \mathrm{kV})$ da subestação de Camaçari II. A configuração da subestação está mostrada na Figura 4.2.

Levando-se em consideração que a região onde se encontra a SE Camaçari II é uma região de cargas industriais (Fábrica da FIAT), fica evidente ser o caso de se levar em conta a análise de inequações de três elementos, conforme citado no início da seção 4.2 , seguindo os procedimentos de rede. 


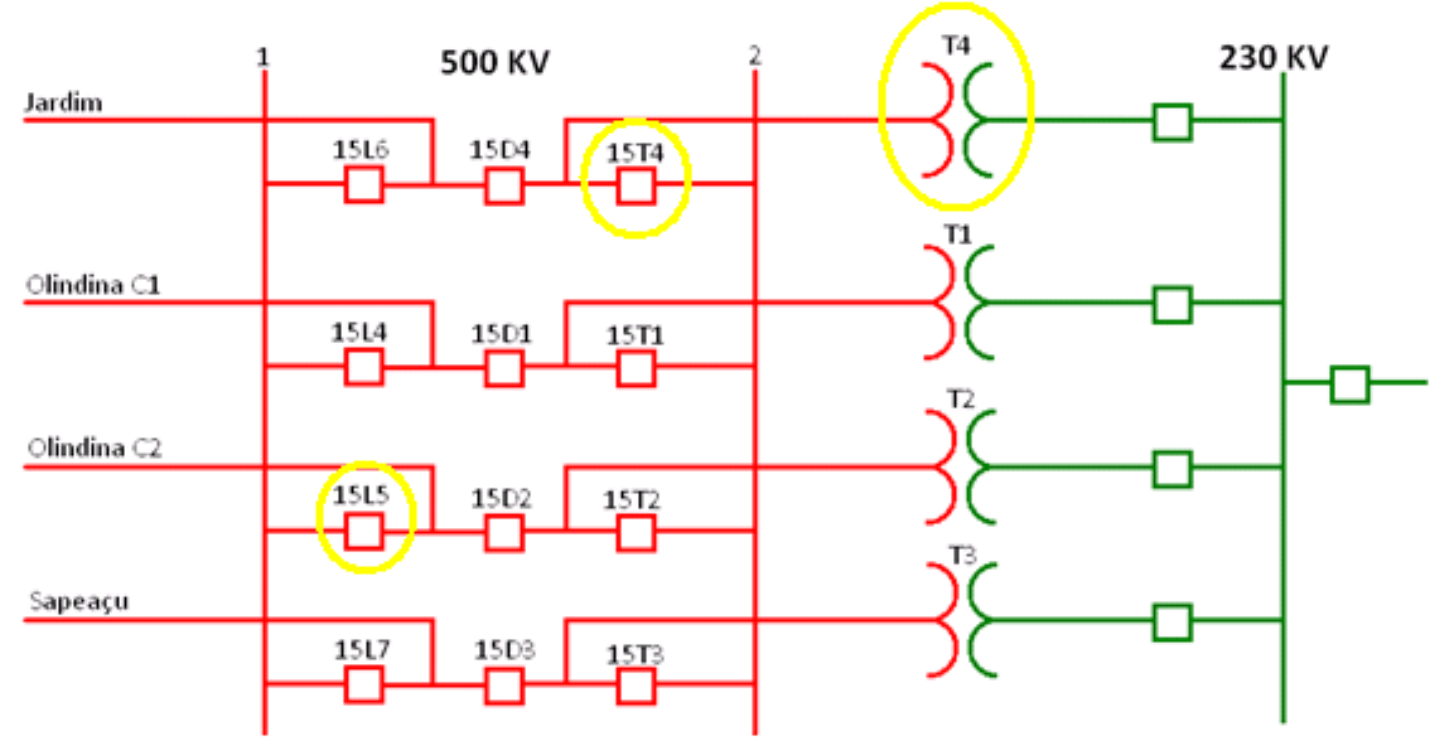

FIGURA 4.2 - CONFIGURAÇÃO DO BARRAMENTO DA SE CAMAÇARI II.

Com o disjuntor 15L5 desligado, caso ocorra a contingência de um dos transformadores 500/230 kV - T1, T3 ou T4 - com falha de disjuntor de interligação com a barra 2 de $500 \mathrm{kV}$, ocorrerá a atuação da proteção diferencial da barra 2. Assim o circuito 2 da linha Olindina-Camaçari II ficará radializada com o transformador 2. Essa configuração pode provocar sobrecarga nesse transformador. Os demais equipamentos continuam ligados da mesma forma. Entretanto na configuração de barra simples.

Para essa análise será considerada a contingência do transformador 4 (por exemplo, por causa de um raio seguido de curto-circuito) com o disjuntor 15D4 se abrindo e com falha do disjuntor 15T4. A falha desse disjuntor provocará a atuação da proteção diferencial da barra 2 de $500 \mathrm{kV}$, desligando os demais disjuntores conectados à barra 2. Assim nessa nova configuração, com o disjuntor 15L5 desligado para manutenção, o circuito 2 da linha Olindina II-Camaçari II ficará radializada com o transformador 2 .

Nos programas de simulação de fluxo de potência, normalmente as duas barras de $500 \mathrm{kV}$ da Figura 4.2 são modeladas em uma única barra. Para que a contingência descrita acima possa ser simulada, são necessários alguns ajustes como mostrado na Figura 4.3 (veja os diagramas do Apêndice A onde são mostrados os fluxos nos equipamentos - e suas modelagens - da região onde se encontra a subestação de Camaçari II). 


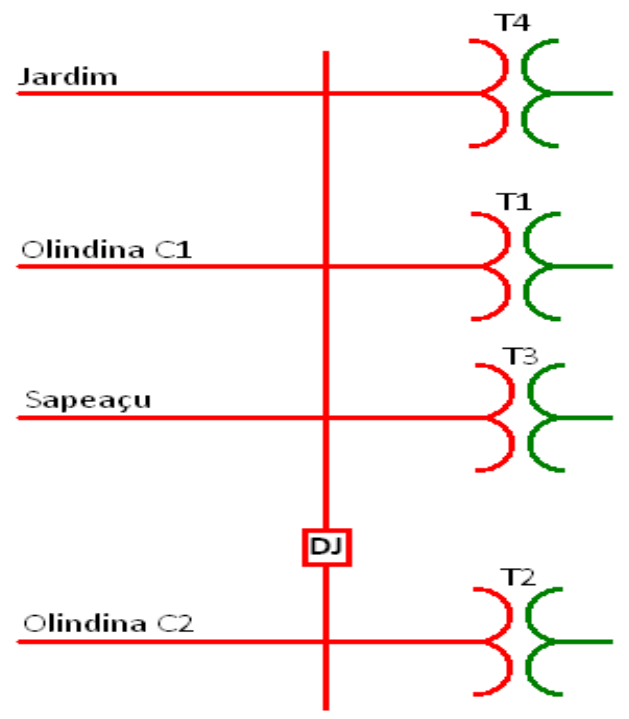

FIGURA 4.3 - MODELAGEM DA SE CAMAÇARI II PARA POSSIBILITAR A SIMULAÇÃO.

O disjuntor (DJ) mostrado na Figura 4.3 modela a proteção diferencial da barra 2 de $500 \mathrm{kV}$ da SE Camaçari II, dada a configuração já descrita. Esse disjuntor será aberto somente no momento em que a proteção diferencial atuar, ou seja, a última contingência.

Aplicando a $1^{\text {a }}$ Lei de Kirchhoff na Figura 4.4, com o disjuntor fechado (configuração do tempo inicial e intermediário), chega-se a Equação (4.16).

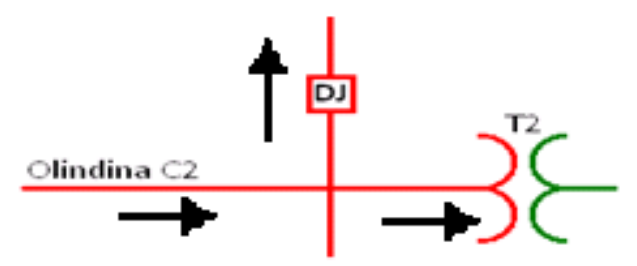

FIGURA 4.4 - APLICAÇÃO DA $1^{\text {a }}$ LEI DE KIRCHHOFF.

$F(D J)=F($ Olin - Cam.C2) $-F(T 2)$

Onde,

F(Olin-Cam.C2) é o fluxo de potência ativa na linha de transmissão Olindina Camaçari II C2, nesse sentido.

F(T2) é o fluxo de potência ativa no transformador 2 de Camaçari II.

Para as simulações foi utilizado o programa Anarede e o caso base de carga média de novembro de 2007 do ONS. 
Após essas constatações, são anotados os fluxos de potência ativa nos equipamentos envolvidos na análise. Os fluxos anotados nesse momento são os fluxos iniciais. Posteriormente desliga-se o transformador 4, simulando a contingência do mesmo. E novamente são anotados os fluxos de potência ativa nos equipamentos envolvidos, os quais estão relacionados ao tempo intermediário. E por fim abre-se o disjuntor que modela a proteção diferencial da barra 2 anotando-se os fluxos de potência ativa dos equipamentos envolvidos.

Para facilitar a análise a Tabela 4.5 foi confeccionada.

Tabela 4.5: Análise da Contingência na SE Camaçari II.

\begin{tabular}{|c|c|c|c|}
\hline Equipamento & $\mathbf{T}_{\mathbf{i}}$ & $\mathbf{T}_{\mathbf{m}}$ & $\mathbf{T}_{\mathbf{f}}$ \\
\hline Transformador 2 & $402,4 \mathrm{MW}$ & $538,7 \mathrm{MW}$ & $605,7 \mathrm{MW}$ \\
\hline Transformador 4 & $458,4 \mathrm{MW}$ & $0 \mathrm{MW}$ & $0 \mathrm{MW}$ \\
\hline Disjuntor & $253,8 \mathrm{MW}$ & $112,1 \mathrm{MW}$ & $0 \mathrm{MW}$ \\
\hline
\end{tabular}

Calculando-se os fatores $\mathrm{K}_{1}, \mathrm{~K}_{2}$ e $\mathrm{K}_{3}$, por meio das Equações (4.8), (4.11) e (4.12).

$$
\begin{aligned}
& K_{3}=\frac{605,7-538,7}{112,1}=0,5977 \\
& K_{1}=\frac{538,7-402,4}{458,4}=0,2973 \\
& K_{2}=\frac{112,1-253,8}{458,4}=-0,3091
\end{aligned}
$$

Fazendo os cálculos dos fatores para a inequação:

$$
K_{1}+K_{2} \times K_{3}=0,1126
$$

Como não houve grandes variações de tensão nas barras adjacentes ao transformador 2, não é necessário redimensionar o limite do equipamento (600 MVA). Assim, a Inequação (4.14) fica da seguinte forma:

$$
F(T 2)+0,1126 \times F(T 4)+0,5977 \times F(D J)<600
$$

Como DJ é um equipamento fictício usado para permitir a análise, é necessário que seja feita a substituição da Equação (4.16) na Equação (4.21), para que os equipamentos envolvidos na inequação sejam os reais, conforme segue abaixo: 


$$
\begin{aligned}
& F(T 2)+0,1126 \times F(T 4)+0,5977 \times[F(\text { Olin }- \text { Cam.C2 })-F(T 2)]<600 \Rightarrow \\
& 0,4023 \times F(T 2)+0,1126 \times F(T 4)+0,5977 \times F(\text { Olin }- \text { Cam.C2 })<600
\end{aligned}
$$

Nessa etapa é necessário fazer a análise de sensibilidade para cada um dos equipamentos e montar a sensibilidade da Inequação (4.22) à variação de geração de cada usina escolhida. Para isso usa-se a mesma metodologia explicada na seção 4.2.

Como nessa época do ano a carga no nordeste cresce muito por causa do calor, as usinas de Paulo Afonso e Luiz Gonzaga estão com geração máxima e com isso a margem de regulação é pequena. Portanto, para ter maior ação nos carregamentos dos equipamentos é melhor que sejam redespachadas as gerações de pequenas usinas que ficam eletricamente mais perto da SE Camaçari II. As usinas escolhidas foram: Termo Bahia, Pedra do Cavalo, Veracel e Itapebi.

Os fatores de influência de cada usina sobre os equipamentos em análise foram adquiridos utilizando a metodologia já explicada. De posse destes foi montada a Tabela 4.6 onde foram calculados os fatores de sensibilidade de cada usina sobre a Inequação (4.22).

Tabela 4.6: Lista de Usinas e fatores de Sensibilidade para Redespacho em Caso de Violação da Inequação de Camaçari II.

\begin{tabular}{|c|c|c|c|c|c|}
\hline Usina & $\begin{array}{c}\text { TR.2 } \\
(\%)\end{array}$ & $\begin{array}{c}\text { TR.4 } \\
(\%)\end{array}$ & $\begin{array}{c}\text { L.T. } \\
\mathbf{( \% )}\end{array}$ & Equação 4.15 (modificada) & $\begin{array}{c}\mathbf{S}_{\mathbf{f}} \\
\mathbf{( \% )}\end{array}$ \\
\hline T. Bahia & -18 & $-20,5$ & $-19,4$ & $0,4023(-18)+0,1126(-20,5)+0,597(-19,4)$ & $-21,1$ \\
\hline P. Cavalo & $-5,3$ & $-6,1$ & $-18,3$ & $0,4023(-5,3)+0,1126(-6,1)+0,597(-18,3)$ & $-13,8$ \\
\hline Veracel & $-2,8$ & $-3,2$ & $-18,4$ & $0,4023(-2,8)+0,1126(-3,2)+0,597(-18,4)$ & $-12,5$ \\
\hline Itapebi & $-2,7$ & $-3,1$ & $-18,2$ & $0,4023(-2,7)+0,1126(-3,1)+0,597(-18,2)$ & $-12,3$ \\
\hline
\end{tabular}

Na Tabela 4.6 o cálculo utilizando a Equação (4.15) precisou de alguns ajustes, pois fica mais simples o cálculo utilizando os fluxos dos equipamentos ao invés de usar a modelagem com disjuntor que simulou a atuação da proteção diferencial da barra 2 . Assim a equação usada ficou bem parecida com a Equação (4.22). 


\section{5- NOVA METODOLOGIA}

$\mathrm{Na}$ elaboração de inequações de três elementos, foi visto que se considera um tempo inicial, um tempo intermediário e um tempo final. Entretanto será que há a necessidade de se considerar o tempo intermediário? A resposta a essa pergunta será dada neste Capítulo.

O tempo intermediário é considerado por causa da diferença de tempo entre a primeira e a segunda contingência. Sabe-se que esse tempo é da ordem de 100 milissegundos (ms), nesse período o sistema não se estabiliza em um ponto de operação (período transitório). Os valores encontrados para esse período são diferentes dos valores considerado uma análise de fluxo de potência. Simplesmente porque não é considerada a falta e o sistema não estabiliza em um ponto de operação, pois o mesmo está passando por um período transitório. $\mathrm{Na}$ análise de fluxo de potência só é considerada a saída de operação de determinado equipamento do sistema. No sistema real, quando ocorre uma falta o sistema busca um novo ponto de operação, o qual é bem diferente do ponto estipulado com apenas a simulação de fluxo de potência.

Foi feita uma simulação dinâmica para o exemplo de Camaçari II da seção 4.2.3. Tais simulações são as ideais para esse tipo de análise, pois as mesmas mostram o comportamento do sistema durante a falta, além de mostrar o período transitório.

Para fazer essas simulações dinâmicas, foram utilizados os programas Anatem, Anat0 e Plotcepel (que em conjunto servem para a análise de transitórios eletromecânicos). Para esta análise, só interessava os carregamentos dos equipamentos em questão, o que está mostrado nas Figuras 5.1, 5.2 e 5.3.

Nas simulações foi usado o caso base de carga média de março de 2008. Para que a análise não perca o seu sentido foi confeccionada a Tabela 5.1 com a mesma metodologia da confecção da Tabela 4.5, entretanto para o caso base de março.

Comparando as Tabelas 4.5 e 5.1 fica evidente que o caso de março está em uma condição energética diferente do caso de novembro, entretanto para a análise que será feita poderá ser utilizado sem maiores problemas. 
Tabela 5.1: Análise de Contingência na SE Camaçari II (caso de março de 2008)

\begin{tabular}{|c|c|c|c|}
\hline Equipamento & $\mathbf{T}_{\mathbf{i}}$ & $\mathbf{T}_{\mathbf{m}}$ & $\mathbf{T}_{\mathbf{f}}$ \\
\hline Transformador 2 & $294,6 \mathrm{MW}$ & $394,4 \mathrm{MW}$ & $433,7 \mathrm{MW}$ \\
\hline Transformador 4 & $334,3 \mathrm{MW}$ & $0 \mathrm{MW}$ & $0 \mathrm{MW}$ \\
\hline Disjuntor & $166,3 \mathrm{MW}$ & $62,8 \mathrm{MW}$ & $0 \mathrm{MW}$ \\
\hline
\end{tabular}

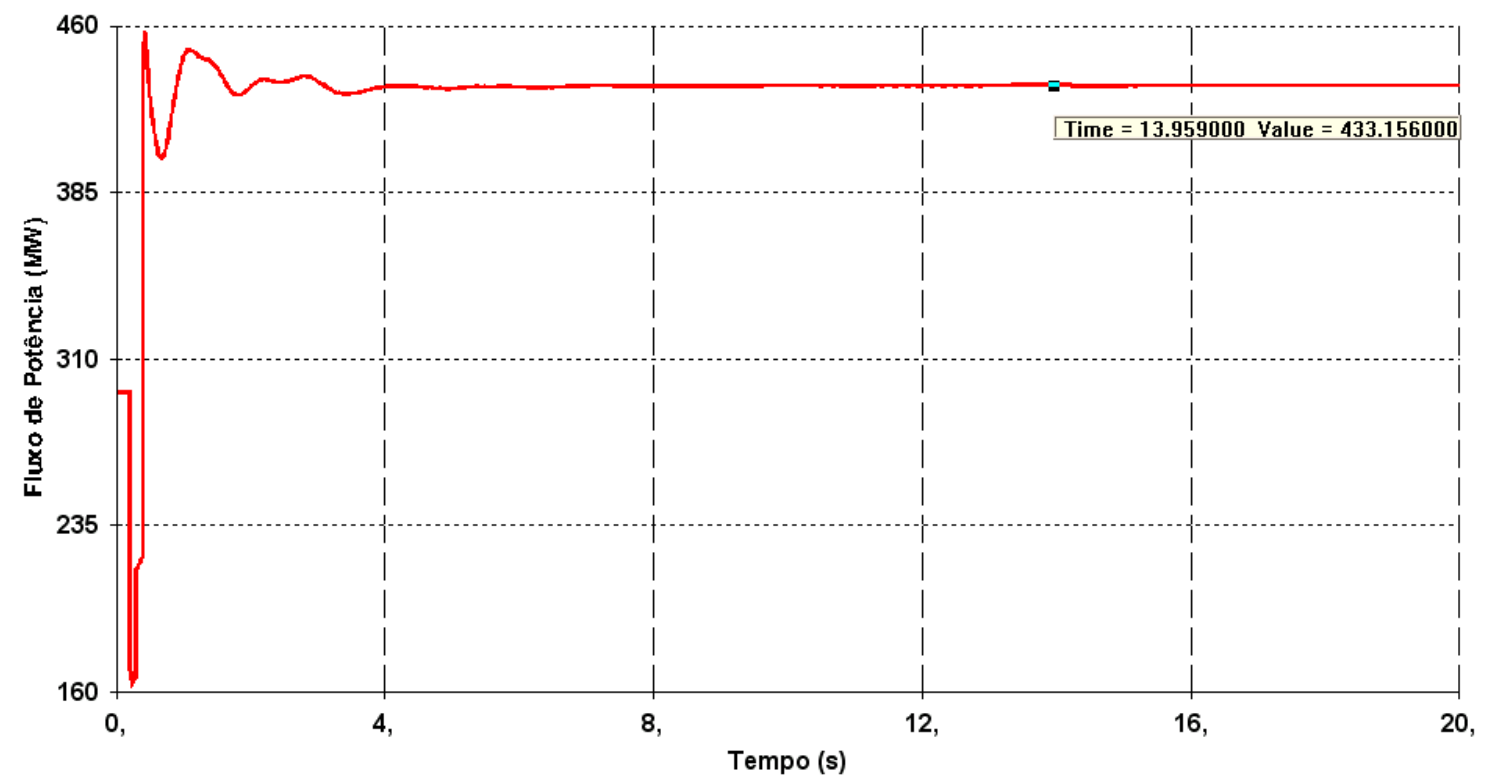

FIGURA 5.1 - FLUXO DE POTÊNCIA NO TRANSFORMADOR 2 DA SE CAMAÇARI II (TEMPO INTERMEDIÁRIO)

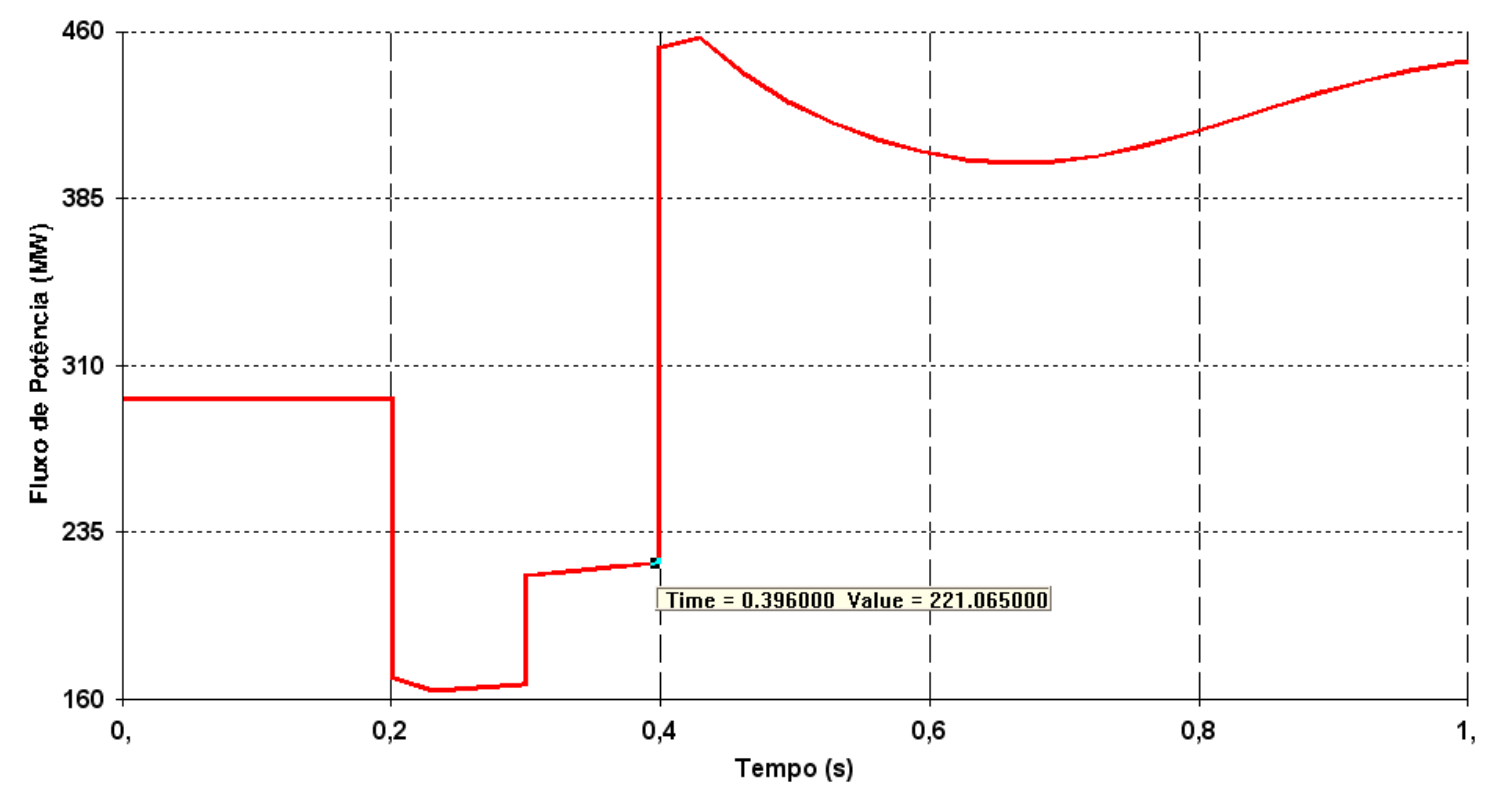

FIGURA 5.2 - ZOOM DO PERÍODO TRANSITÓRIO DO FLUXO DE POTÊNCIA DO TRANSFORMADOR 2 DA SE CAMAÇARI II (TEMPO INTERMEDIÁRIO). 


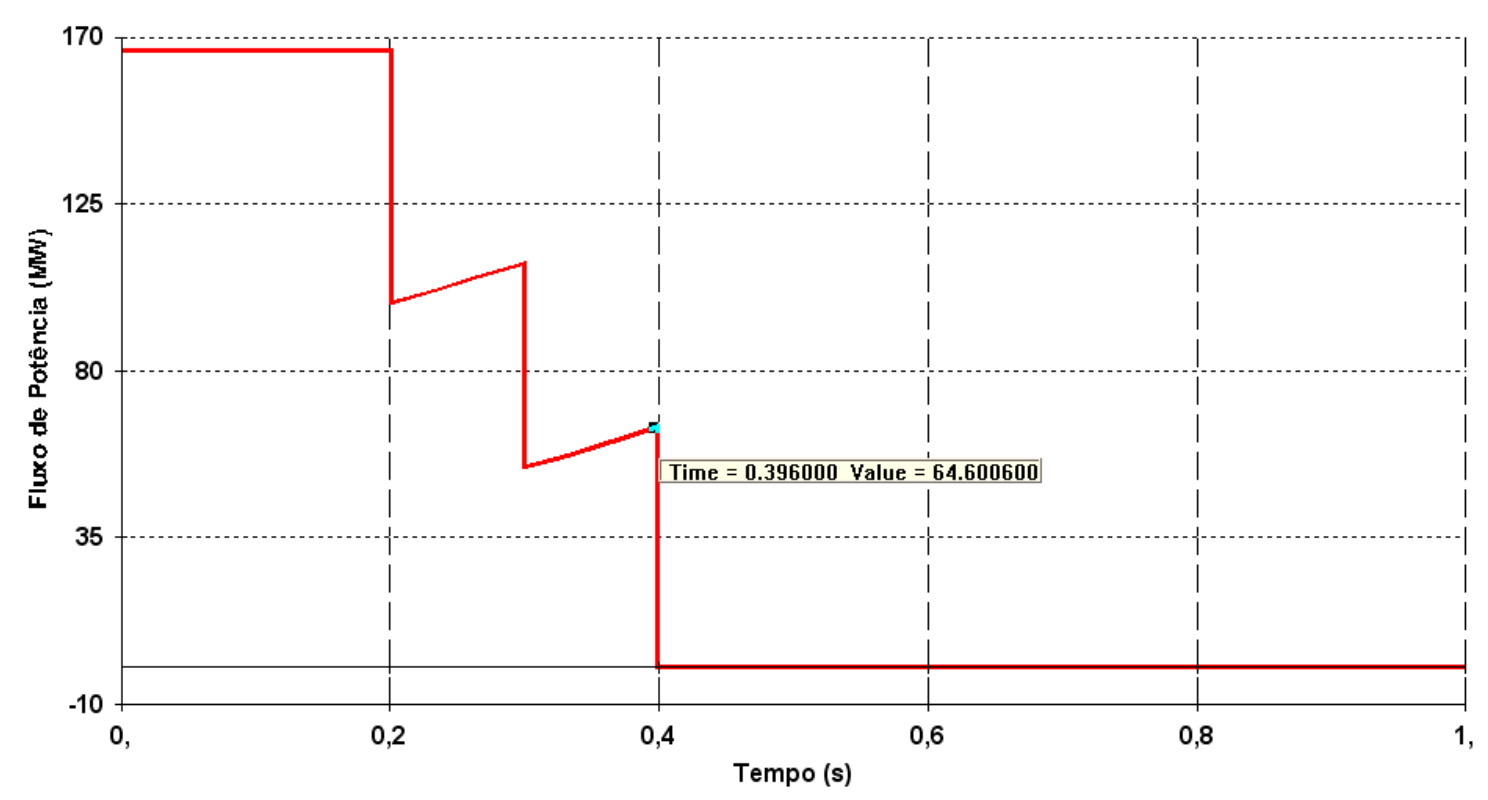

FIGURA 5.3 - FLUXO DE POTÊNCIA NO DISJUNTOR DE MODELAGEM DA PROTEÇÃO DIFERENCIAL DA BARRA 2 DA SE CAMAÇARI II (TEMPO INTERMEDIÁRIO).

A seqüência dos eventos na simulação dinâmica é a seguinte: $200 \mathrm{~ms}$ de regime na configuração inicial. Nesse momento é aplicado um curto-circuito monofásico no transformador 4. Em $300 \mathrm{~ms}$ de simulação é aberto o transformador 4, simulando a atuação da primeira proteção. Em 400 ms de simulação é aberto o disjuntor (DJ), simulando a atuação da proteção diferencial da barra 2 eliminando o curtocircuito. Depois desses eventos continua-se a simulação até 20 segundos para saber em qual ponto o sistema estabilizará.

Observando as Figuras 5.2 e 5.3, percebe-se o que o ponto de operação intermediário pelo qual o sistema passou é muito diferente do ponto de operação estipulado pela simulação de fluxo de potência (veja Tabela 5.1). Lembrando, que nesse momento, o sistema está em regime transitório. Essa situação era esperada, pois na simulação de fluxo de potência a falta não é considerada e o sistema é modelado em regime permanente. Ao observar a Figura 5.1, vê-se que o ponto em que o sistema estabilizou depois do período transitório ficou bem próximo do ponto de operação final estipulado pala simulação no Anarede.

Posteriormente, foi feita uma nova simulação dinâmica, onde as contingências foram consideradas simultâneas. Ou seja, aconteceram ao mesmo tempo. O objetivo dessa nova simulação é ver em qual ponto de operação o sistema irá estabilizar. A nova simulação está mostrada na Figura 5.4. 


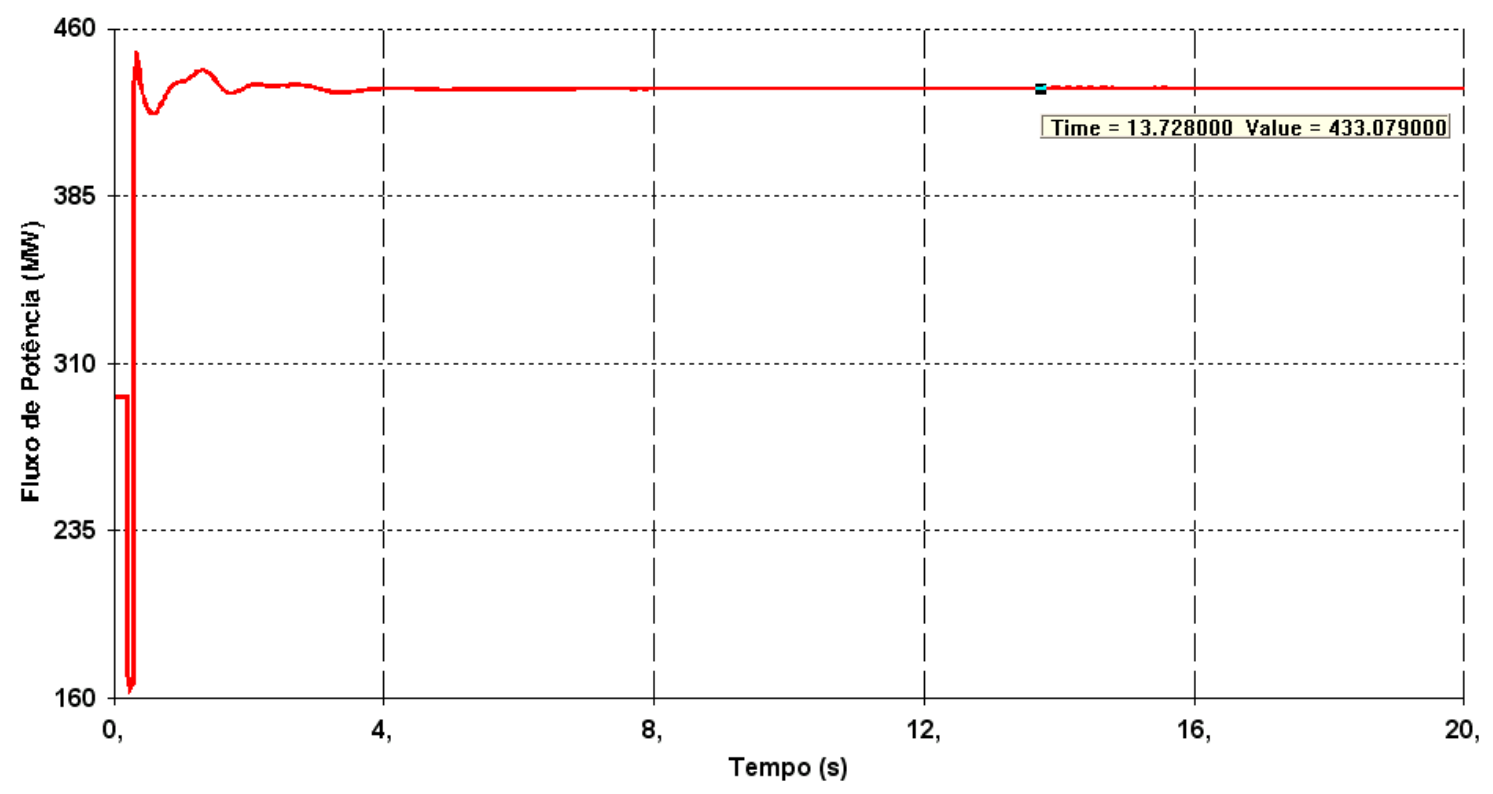

FIGURA 5.4 - FLUXO DE POTÊNCIA NO TRANSFORMADOR 2 DA SE CAMAÇARI II (CONTINGÊNCIAS SIMULTÂNEAS)

A seqüência da nova simulação é simples: $200 \mathrm{~ms}$ de regime na configuração inicial. Nesse momento aplica-se um curto-circuito monofásico no transformador 4. Em $300 \mathrm{~ms}$ o transformador 4 e o disjuntor (DJ) são abertos simulando a atuação da primeira proteção e da proteção diferencial da barra 2 eliminando o curto-circuito. Depois desses eventos continua-se a simulação até 20 segundos para saber em qual ponto o sistema estabilizará.

Observando a Figura 5.4, fica evidente que o ponto de operação onde o sistema estabiliza após o período transitório é muito próximo do verificado na simulação dinâmica anterior (veja Figura 5.1) e também da simulação de fluxo de potência (veja Tabela 5.1). Assim, considerando-se as contingências simultâneas chega-se ao mesmo resultado de quando é considerado o tempo intermediário (considerando somente o regime permanente do sistema). Nesse momento percebe-se que o ponto de operação final dos equipamentos independe de qual o "caminho" o sistema percorreu.

Do ponto de vista do carregamento, o atendimento do critério N-1 será alcançado quando o carregamento dos equipamentos em regime permanente não ultrapassar seu limite nominal.

Pode-se entender esse fenômeno simplesmente considerando que o ponto final de operação do sistema está diretamente relacionado com a topologia final da rede de transmissão. 
Esquecendo um pouco a análise dinâmica. Tenta-se, nesse momento, provar algebricamente a não necessidade de considerar o tempo intermediário.

Partindo do pressuposto que as contingências são simultâneas, pode-se aplicar as Equações (4.2) e (4.3) (da teoria das Inequações de Dois Elementos). Basta considerar que o fluxo de potência ativa no equipamento 2 é um somatório dos fluxos de potência ativa dos equipamentos que sofrerão as contingências (F2 + F3). Assim, as Equações (4.2) e (4.3) ficam da seguinte forma, respectivamente.

$$
\begin{aligned}
& F 1_{f}^{\prime}=F 1_{i}+K_{a} \times\left(F 2_{i}+F 3_{i}\right) \\
& K_{a}=\frac{F 1_{f}-F 1_{i}}{F 2_{i}+F 3_{i}}
\end{aligned}
$$

$\mathrm{O}$ fator $\mathrm{K}_{\mathrm{a}}$ é a influência no equipamento 1 em relação à saída simultânea dos equipamentos 2 e $3 . F 1_{\mathrm{f}}$ ' é o fluxo final no equipamento 1 dada à saída simultânea dos equipamentos 2 e 3 .

Dados os fluxos iniciais e o fluxo final, a Equação (4.13) monta um sistema de equações o qual trata de uma equação com duas variáveis, onde as variáveis são os coeficientes relacionados com os fluxos nos equipamentos 2 e $3\left(\mathrm{~K}_{1}+\mathrm{K}_{2} \mathrm{~K}_{3}\right.$ e $\left.\mathrm{K}_{3}\right)$. Esse tipo de sistema tem como solução infinitas combinações de valores para as variáveis. Assim, a solução dada considerando o tempo intermediário, é apenas uma delas. Portanto, o sistema tem outras soluções, que podem servir de alternativa para a análise de contingências, ficando a critério do analista escolher a solução que mais the for confortável. Neste Capítulo, a solução procurada é uma solução que não envolva a necessidade do tempo intermediário.

Como mostrado anteriormente o ponto de operação final do sistema é mesmo independente de como as contingências aconteceram. $O$ que interessa é que as contingências aconteceram. Logo pode se igualar os fluxos finais $F 1_{\mathrm{f}}$ e $F 1_{\mathrm{f}}$, o que provoca uma igualdade entre as Equações (4.13) e (5.1), como segue:

$$
F 1_{i}+\left(K_{1}+K_{2} \times K_{3}\right) \times F 2_{i}+K_{3} \times F 3_{i}=F 1_{i}+K_{a} \times\left(F 2_{i}+F 3_{i}\right)
$$

Comparando o lado direito da Equação (5.3) com o lado esquerdo, verifica-se que a única forma de essa igualdade ser verdadeira, já que os fluxos nos equipamentos são conhecidos, é se: 


$$
K_{3}=K_{1}+K_{2} \times K_{3}=K_{a}
$$

Desenvolvendo a primeira igualdade da Equação (5.4):

$$
K_{3}-K_{3} \times K_{2}=K_{1} \Rightarrow K_{3} \times\left(1-K_{2}\right)=K_{1} \Rightarrow K_{3}=\frac{K_{1}}{1-K_{2}}
$$

Substituindo as Equações (4.8), (4.11) e (4.12) na Equação (5.5):

$$
\begin{aligned}
& \frac{F 1_{f}-F 1_{m}}{F 3_{m}}=\frac{\frac{F 1_{m}-F 1_{i}}{F 2_{i}}}{1-\left(\frac{F 3_{m}-F 3_{i}}{F 2_{i}}\right)} \Rightarrow \frac{F 1_{f}-F 1_{m}}{F 3_{m}}=\frac{\frac{F 1_{m}-F 1_{i}}{F 2_{i}}}{\frac{F 2_{i}-F 3_{m}+F 3_{i}}{F 2_{i}}} \Rightarrow \\
& \frac{F 1_{f}-F 1_{m}}{F 3_{m}}=\frac{F 1_{m}-F 1_{i}}{F 2_{i}-F 3_{m}+F 3_{i}} \Rightarrow F 3_{m}\left(F 1_{m}-F 1_{i}\right)=\left(F 1_{f}-F 1_{m}\right)\left(F 2_{i}-F 3_{m}+F 3_{i}\right) \Rightarrow \\
& F 3_{m}\left(F 1_{m}-F 1_{i}\right)=F 1_{f}\left(F 2_{i}-F 3_{m}+F 3_{i}\right)-F 1_{m}\left(F 2_{i}-F 3_{m}+F 3_{i}\right) \Rightarrow \\
& F 3_{m} F 1_{m}-F 3_{m} F 1_{i}=F 1_{f}\left(F 2_{i}-F 3_{m}+F 3_{i}\right)-F 1_{m}\left(F 2_{i}-F 3_{m}+F 3_{i}\right) \Rightarrow \\
& F 1_{m}\left(F 3_{m}+F 2_{i}-F 3_{m}+F 3_{i}\right)=F 1_{f}\left(F 2_{i}-F 3_{m}+F 3_{i}\right)+F 3_{m} F 1_{i} \Rightarrow \\
& F 1_{m}=\frac{F 1_{f} F 2_{i}+F 1_{f} F 3_{i}-F 1_{f} F 3_{m}+F 1_{i} F 3_{m}}{F 2_{i}+F 3_{i}} \Rightarrow F 1_{m}=\frac{F 1_{f}\left(F 2_{i}+F 3_{i}\right)+F 3_{m}\left(-F 1_{f}+F 1_{i}\right)}{F 2_{i}+F 3_{i}} \Rightarrow \\
& F 1_{m}=F 1_{f}+\frac{F 3_{m}\left(-F 1_{f}+F 1_{i}\right)}{F 2_{i}+F 3_{i}}
\end{aligned}
$$

Quando a Equação (5.4) é satisfeita o fluxo intermediário no equipamento 1 é dado pela Equação (5.6). Como a definição da Equação (4.8) é função do fluxo intermediário no equipamento 1, pode-se substituir a Equação (5.6) na Equação (4.8), como segue:

$$
\begin{aligned}
& K_{3}=\frac{F 1_{f}-\left[F 1_{f}+\frac{F 3_{m}\left(-F 1_{f}+F 1_{i}\right)}{F 2_{i}+F 3_{i}}\right]}{F 3_{m}} \Rightarrow K_{3}=\frac{-1}{F 3_{m}}\left[\frac{F 3_{m}\left(-F 1_{f}+F 1_{i}\right)}{F 2_{i}+F 3_{i}}\right] \Rightarrow \\
& K_{3}=\frac{F 1_{f}-F 1_{i}}{F 2_{i}+F 3_{i}}
\end{aligned}
$$

Observando o resultado para $\mathrm{K}_{3}$, quando a Equação (5.4) é satisfeita, verificase que ele não depende do tempo intermediário e é igual ao $K_{a}$ (Equação (5.2)) estipulado. Entretanto é necessário provar também para a segunda igualdade da Equação (5.4), $\mathrm{K}_{1}+\mathrm{K}_{2} \mathrm{~K}_{3}$. 
Da Equação (4.11):

$$
\begin{aligned}
& K_{1}=\frac{F 1_{f}+\frac{F 3_{m}\left(-F 1_{f}+F 1_{i}\right)}{F 2_{i}+F 3_{i}}-F 1_{i}}{F 2_{i}} \Rightarrow K_{1}=\frac{1}{F 2_{i}}\left[\frac{\left(F 1_{f}-F 1_{i}\right)\left(F 2_{i}+F 3_{i}\right)-F 3_{m}\left(F 1_{f}-F 1_{i}\right)}{F 2_{i}+F 3_{i}}\right] \Rightarrow \\
& K_{1}=\frac{1}{F 2_{i}}\left[\frac{\left(F 1_{f}-F 1_{i}\right)\left(F 2_{i}+F 3_{i}-F 3_{m}\right)}{F 2_{i}+F 3_{i}}\right]
\end{aligned}
$$

Desenvolvendo o produto $\mathrm{K}_{2} \mathrm{~K}_{3}$, já considerando o novo valor de $\mathrm{K}_{3}$ e a Equação (4.12):

$$
K_{2} K_{3}=\left(\frac{F 3_{m}-F 3_{i}}{F 2_{i}}\right)\left(\frac{F 1_{f}-F 1_{i}}{F 2_{i}+F 3_{i}}\right) \Rightarrow K_{2} K_{3}=\frac{1}{F 2_{i}}\left[\frac{\left(F 3_{m}-F 3_{i}\right)\left(F 1_{f}-F 1_{i}\right)}{F 2_{i}+F 3_{i}}\right]
$$

Somando as Equações (5.8) e (5.9):

$$
\begin{aligned}
& K_{1}+K_{2} K_{3}=\frac{\left(F 1_{f}-F 1_{i}\right)\left(F 2_{i}+F 3_{i}-F 3_{m}\right)+\left(F 3_{m}-F 3_{i}\right)\left(F 1_{f}-F 1_{i}\right)}{F 2_{i}\left(F 2_{i}+F 3_{i}\right)} \Rightarrow \\
& K_{1}+K_{2} K_{3}=\frac{\left(F 1_{f}-F 1_{i}\right)\left(F 2_{i}+F 3_{i}-F 3_{m}+F 3_{m}-F 3_{i}\right)}{F 2_{i}\left(F 2_{i}+F 3_{i}\right)} \Rightarrow K_{1}+K_{2} K_{3}=\frac{\left(F 1_{f}-F 1_{i}\right) F 2_{i}}{F 2_{i}\left(F 2_{i}+F 3_{i}\right)} \Rightarrow \\
& K_{1}+K_{2} K_{3}=\frac{F 1_{f}-F 1_{i}}{F 2_{i}+F 3_{i}}
\end{aligned}
$$

Verificando a Equação (5.10), percebe-se que ela também não depende de nenhuma grandeza relacionada ao tempo intermediário e que ela é igual ao fator $\mathrm{K}_{\mathrm{a}}$ (Equação (5.2)) estipulado. Assim, valida-se por completo a suposição de que há uma solução do sistema de equações independente dos fluxos intermediários dos equipamentos envolvidos na análise das contingências.

Logo, fica evidente, observando as Equações (5.7) e (5.10), que do ponto de vista de carregamento não é necessário considerar o tempo intermediário quando ocorrer contingências em tempos diferentes. Não faz diferença se as contingências ocorrerem simultaneamente ou em tempos diferentes. Como já foi explicado o que importa para essa análise é a configuração final da rede. Está provado matematicamente que há uma nova alternativa para a análise de contingências, as quais se encaixam nos critérios das Inequações de três elementos, não havendo a necessidade de se considerar o tempo intermediário. 


\section{1- APLICAÇÃO DA NOVA METODOLOGIA.}

Agora essa nova metodologia será aplicada no exemplo da SE Camaçari II da seção 4.2.3 e seus resultados serão comparados com os resultados da simulação de fluxo de potência. A aplicação será feita considerando-se os dados obtidos com o caso base de novembro de 2007, para que as comparações possam ser efetuadas.

Foram efetuados os mesmos procedimentos para inequações de dois elementos, entretanto considerou-se o fluxo no equipamento 2 das Equações (4.2) e (4.3) como o somatório dos fluxos no transformador 4 e no disjuntor (DJ) de modelagem da proteção diferencial da barra 2. Os dados estão mostrados na Tabela 5.2.

Tabela 5.2: Nova Metodologia para Inequações de Três Elementos - Subestação de Camaçari II

\begin{tabular}{|c|c|c|}
\hline Equipamento & Tempo Inicial & Tempo Final \\
\hline Transformador 2 & $402,4 \mathrm{MW}$ & $605,7 \mathrm{MW}$ \\
\hline Transformador 4 & $458,4 \mathrm{MW}$ & $0 \mathrm{MW}$ \\
\hline Disjuntor & $253,8 \mathrm{MW}$ & $0 \mathrm{MW}$ \\
\hline
\end{tabular}

Calculando o fator $\mathrm{K}_{\mathrm{a}}$, usando a Equação (5.2):

$K_{a}=\frac{605,7-402,4}{458,4+253,8}=0,2855$

Assim a Equação (5.1) fica da seguinte forma:

$$
F(T 2)_{f}^{\prime}=F(T 2)+0,2855 \times[F(T 4)+F(D J)]
$$

Substituindo-se a Equação (4.16) na Equação (5.12), tem-se:

$$
\begin{aligned}
& F(T 2)_{f}^{\prime}=F(T 2)+0,2855 \times[F(T 4)+F(\text { Olin }- \text { Cam.C2 })-F(T 2)] \Rightarrow \\
& F(T 2)_{f}^{\prime}=0,7145 \times F(T 2)+0,2855 \times[F(T 4)+F(\text { Olin }- \text { Cam.C2 })]
\end{aligned}
$$

Fazendo-se o cálculo de $\mathrm{F}(\mathrm{T} 2)_{\mathrm{f}}{ }^{\prime}$ com os valores das grandezas iniciais, para o caso de carga média, chega-se ao seguinte resultado:

$$
F(T 2)_{f}^{\prime}(\text { média })=605,76 M W
$$

Nota-se que o resultado encontrado para $\mathrm{F}(\mathrm{T} 2)_{\mathrm{f}}$ ' pruduz uma excelente aproximação, pois o valor estimado para o fluxo final do transformador 2 ficou muito 
próximo ao valor simulado (veja as Tabelas 4.5 e 5.2). Entretanto, é muito fácil provar que se trata de uma boa aproximação no caso base onde foi elaborada a equação da estimativa do fluxo final de um equipamento. Para que não fiquem quaisquer dúvidas, será feito o cálculo da Equação (5.13) com os valores dos fluxos iniciais, do caso base de carga pesada de novembro de 2007, dos equipamentos envolvidos, pois em tempo real dificilmente os fluxos serão exatamente iguais aos verificados na Tabela 5.2. Eles serão próximos, mas não iguais.

A Tabela 5.3 mostra os fluxos iniciais e finais nos equipamentos envolvidos na análise para o caso base de carga pesada.

Tabela 5.3: Nova Metodologia para Inequações de Três Elementos - Subestação de Camaçari II

\begin{tabular}{|c|c|c|}
\hline Equipamento & Tempo Inicial & Tempo Final \\
\hline Transformador 2 & $369,2 \mathrm{MW}$ & $583,8 \mathrm{MW}$ \\
\hline Transformador 4 & $428,7 \mathrm{MW}$ & $0 \mathrm{MW}$ \\
\hline Olin-Cam. C2 & $650,9 \mathrm{MW}$ & - \\
\hline
\end{tabular}

Utilizando a Equação $(5,13)$, para calcular o fluxo final do transformador 2, no período de carga pesada, chega-se a:

$$
F(T 2)_{f}^{\prime}(\text { pesada })=572,02 M W
$$

Comparando o resultado da Equação (5.15) como valor verificado na simulação $-\mathrm{F}(\mathrm{T} 2)_{\mathrm{f}}($ pesada $)=583,8$ na simulação, verifica-se um erro de $2 \%$. Como trata-se de uma aproximação linear e o processo de fluxo de potência é não-linear e considerando as imprecisões de medição que poderão ocorrer em tempo real, pode-se dizer que a inequação formada a partir da Equação (5.13) é uma boa alternativa para monitorar o carregamento do transformador 2, dadas as contingências estudadas. 


\section{6- CONCLUSÃO}

Este trabalho teve como objetivo o estudo do comportamento de sistemas elétricos de potência, dada uma ou mais contingências. Na primeira parte foi abordada a forma como um sistema elétrico de potência é constituído, falando sobre o equilíbrio entre geração e carga, que é base para toda a análise feita.

A parte seguinte tratou qualitativamente da operação de sistemas elétricos de potência com ênfase para o SIN. Foram abordados temas como o controle de tensão e controle de freqüência de oscilação de sistemas elétricos. Também foi tratada a questão do critério N-1 que deve ser atendido por todo o sistema. Normalmente esse critério é atendido pela topologia da rede. Entretanto há situações em que são necessários artifícios para conseguir o atendimento a ele.

No Capítulo 4 foram abordados os artifícios utilizados na operação do SIN para atendimento do critério N-1. Em grande maioria esse atendimento é alcançado pelo monitoramento, em tempo real, das inequações de carregamento de equipamentos.

Em caso de contingência os carregamentos dos equipamentos remanescentes podem ultrapassar seus limites nominais, causando prejuízo nos equipamentos e possíveis atuações de proteções, podendo levar ao desabastecimento de energia elétrica em algumas regiões.

Para se evitar esse transtorno, as inequações tentam prever, antes de ocorrer as contingências, quais serão os carregamentos dos equipamentos remanescentes caso ocorra a contingência. Assim o operador do sistema pode controlar os fluxos de potência nos equipamentos relacionados para evitar que, em caso de contingência, haja sobrecarga.

No Capítulo 5, foi provado inicialmente por dados empíricos, que os carregamentos finais dos equipamentos remanescentes dependem da topologia final da rede. Com base nessa informação foi suposta uma nova forma de análise a qual provouse matematicamente a não necessidade de utilizar a análise de tempo intermediário (quando há possibilidade de ocorrer contingências duplas de equipamentos em tempos diferentes), usada na formulação das inequações de três elementos. 
Posteriormente foram feitas as análises, com a nova metodologia, no exemplo de inequação de três elementos. Os resultados obtidos tiveram uma excelente precisão em comparação aos resultados encontrados com a metodologia tradicional. Lembrando, que essas comparações foram feitas para os períodos de carga média e de carga pesada.

Assim a nova metodologia para análise de contingências duplas não simultâneas serve como alternativa ao método tradicional, para que os analistas usem, caso sintam-se a vontade.

Fica como sugestão para trabalhos futuros as análises dinâmicas envolvendo o critério N-1, pois o SIN também deve estar preparado para suportar as oscilações do sistema em caso de contingências. 


\section{REFERÊNCIAS BIBLIOGRÁFICAS}

[1] Programa ANAREDE - Análise de Redes - V09.01.08 - Manual do Usuário. CEPEL Centro de Pesquisa de Energia Elétrica, Rio de Janeiro, RJ, 2007.

[2] da Cruz, I. S., Comandos Básicos do Programa ANAREDE, Operador Nacional do Sistema Elétrico, Brasília, DF, 2005.

[3] NT-136/2004 Metodologia para Elaboração de Inequações para Monitoramento de carregamento. Operador Nacional do Sistema Elétrico, Rio de Janeiro, RJ, 2004.

[4] da Silva, R. M., Roteiro para Uso dos Programs ANATEM, ANAT0, e PLOTCEPEL, Operador Nacional do Sistema Elétrico, Brasília, DF, 2006.

[5] Programa ANATEM - Análise de Transitórios Eletromecânicos - Manual do Usuário. CEPEL - Centro de Pesquisa de Energia Elétrica, Rio de Janeiro, RJ, 2007.

[6] Freitas, F. D., Notas de Aula de Análise de Sistemas de Potência, Universidade de Brasília, Brasília, DF, 2007.

[7] Rita, C. A. da S., Simulação de Transitórios Eletromecânicos de Sistemas de Potência, Universidade de Brasília, Brasília, DF, 2003.

[8] de Almeida, W. G., Freitas, F. D., Circuitos Polifásicos, FINATEC, Brasília, DF, 1995.

[9] Procedimentos de Rede - módulos 6, 10 e 23, Operador Nacional do Sistema Elétrico, Rio de Janeiro, RJ, 2007. 
APÊNDICE A

1. DiAgRAMAS da REgião da SUBESTAÇÃo DE TIJUCO PRETO

1.1. ANTES DA CONTINGÊNCIA (SEÇÃO 4.1.3)

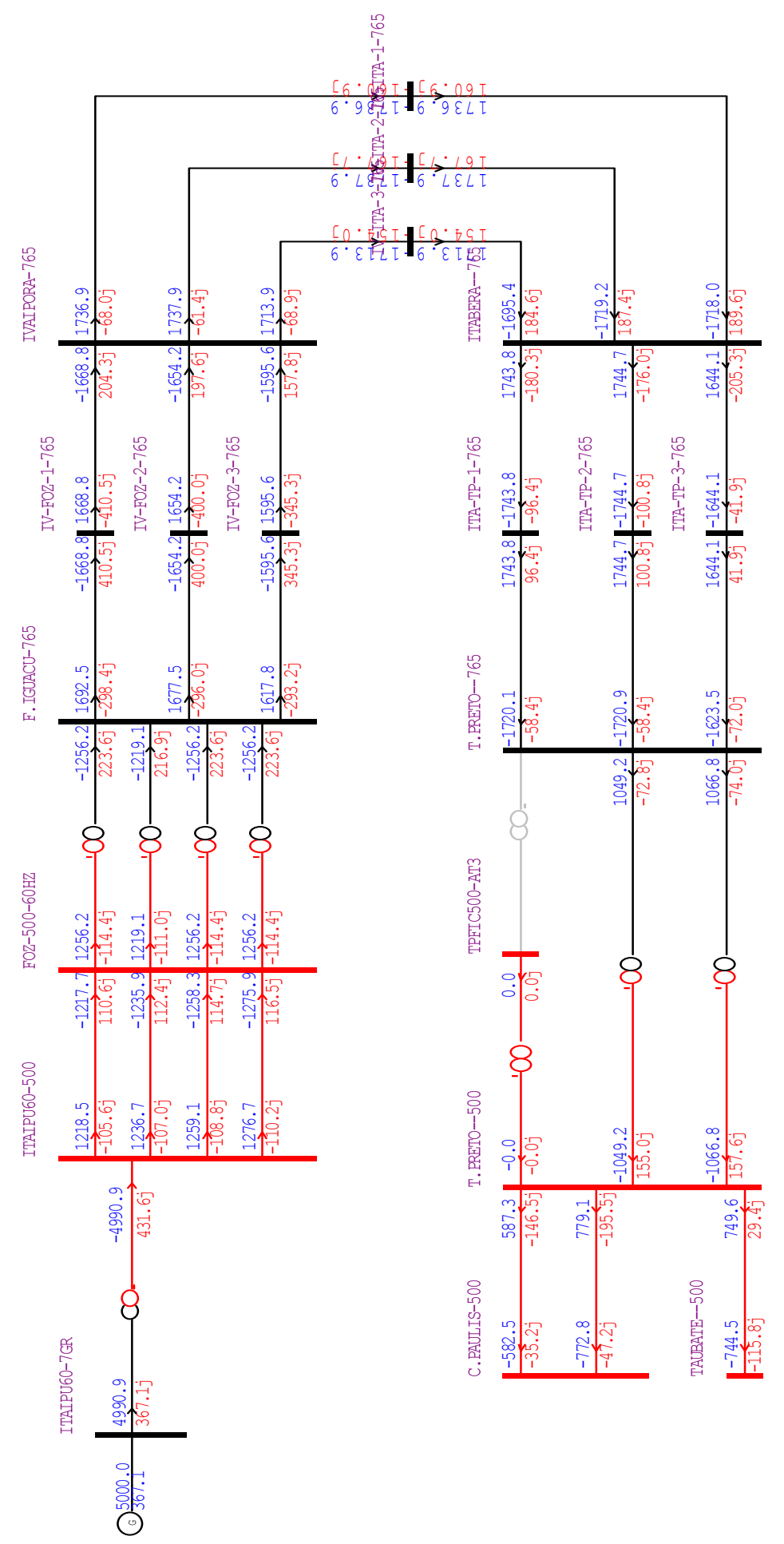


1.2. DEPOIS DA CONTINGÊNCIA (SEÇÃO 4.1.3)

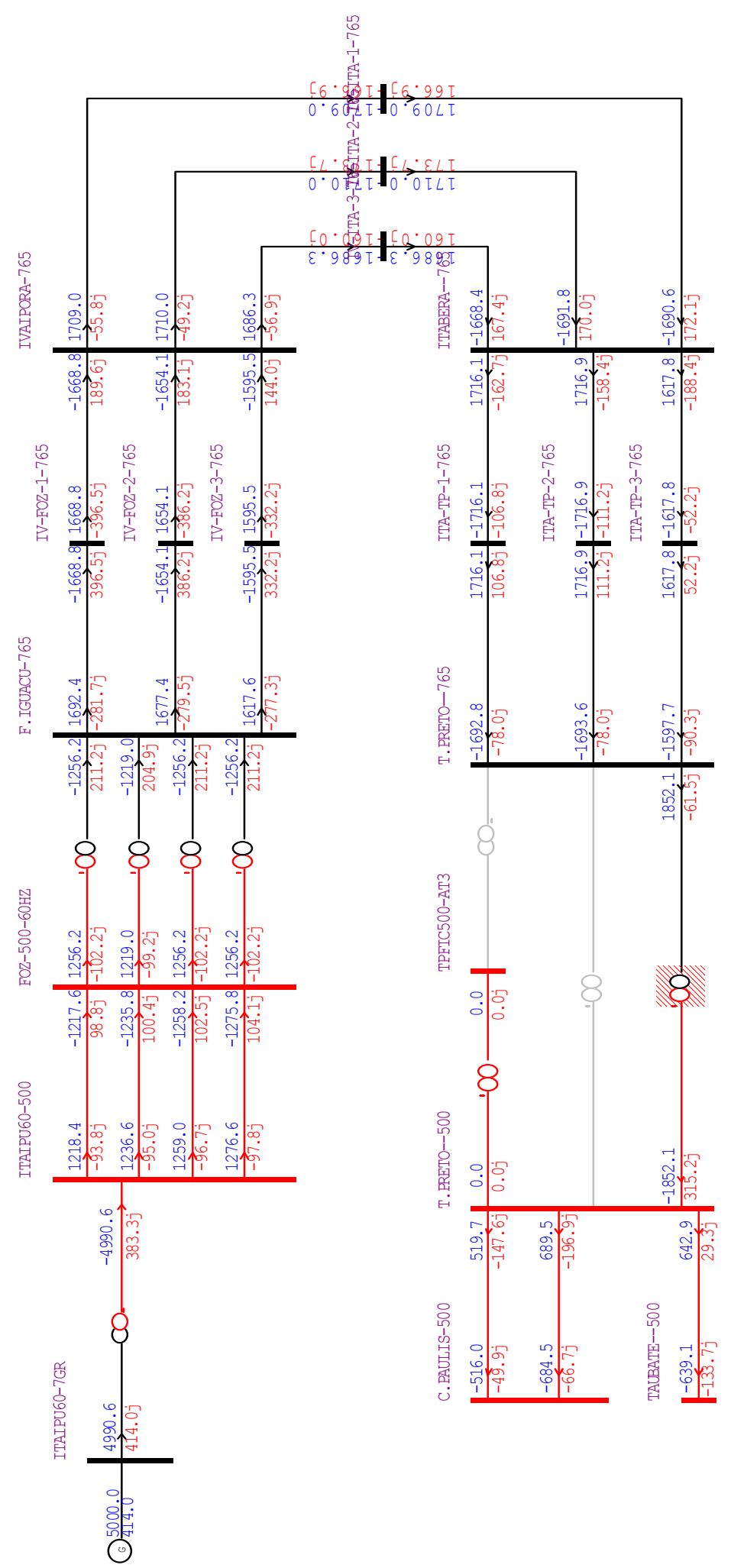


2. DIAGRAMAS DA REGIÃo DA SUBESTAÇÃO DE CAMAÇARI II

2.1. MODELAGEM NO ANAREDE (SEÇÃO 4.2.3)

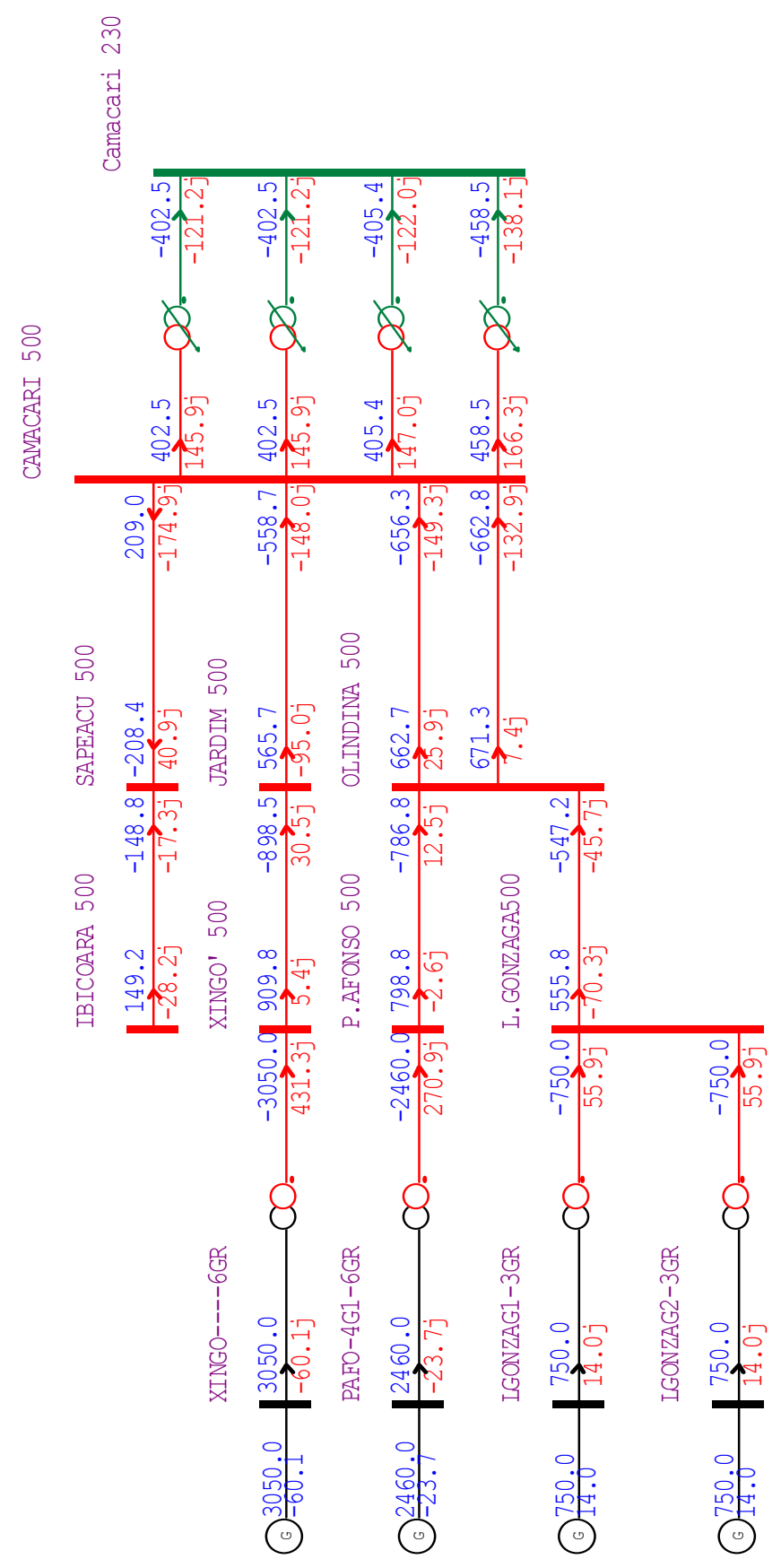


2.2. TEMPO INICIAL COM A MODELAGEM DO DISJUNTOR (DJ) (SEÇÃO 4.2.3)

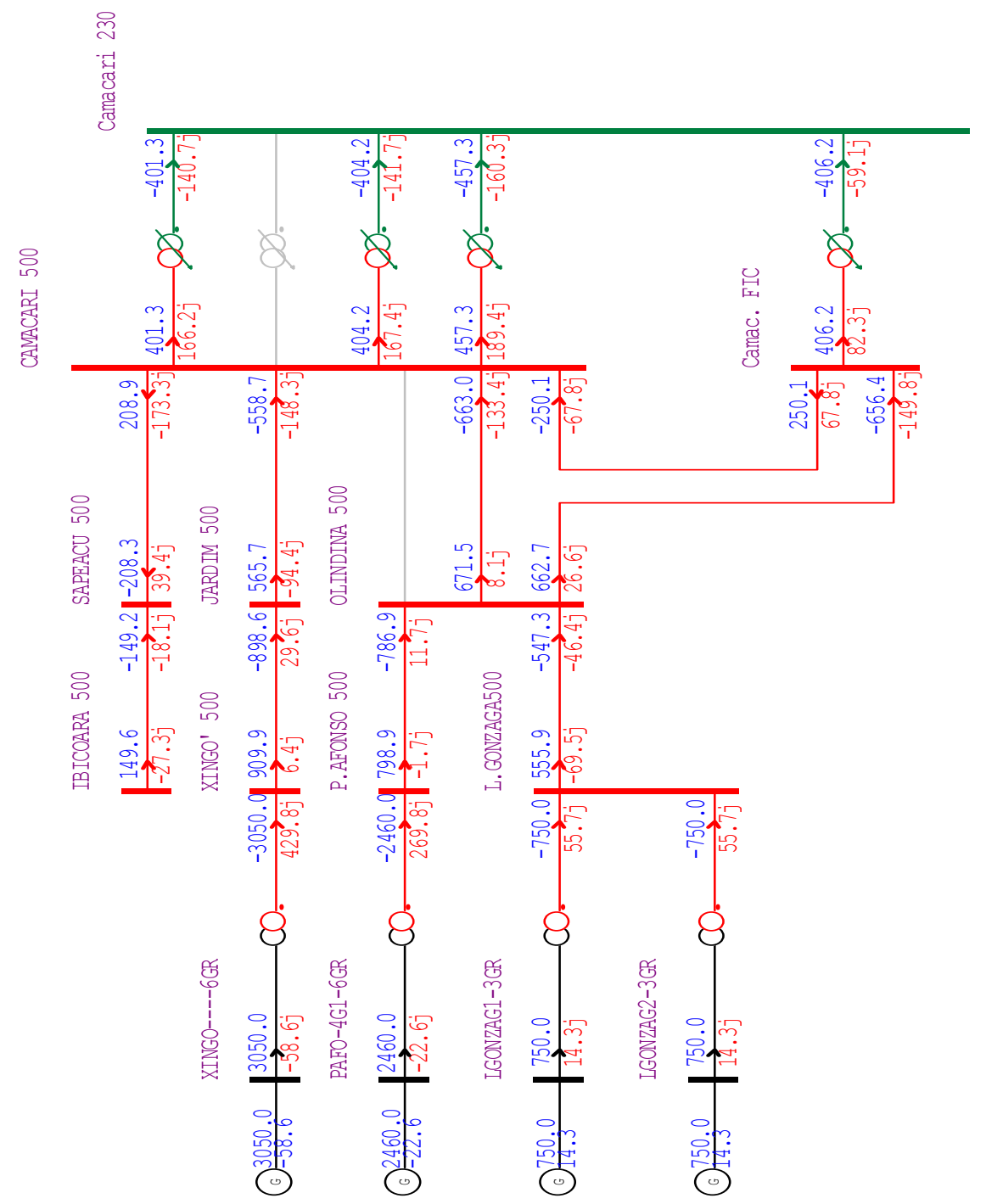

\section{OBSERVAÇÕES:}

O disjuntor (DJ) é modelado por uma linha de transmissão com resistência zero, reatância desprezível e suceptância zero. Essa modelagem no Anarede Windows faz com que haja pequenas variações dos fluxos nos equipamentos sob análise em relação aos verificados na mesma modelagem no Anarede DOS, entretanto sem causar prejuízos das análises. 
2.3. TEMPO INTERMEDIÁRIO COM A MODELAGEM DO DISJUNTOR (DJ) (SEÇÃO 4.2.3)

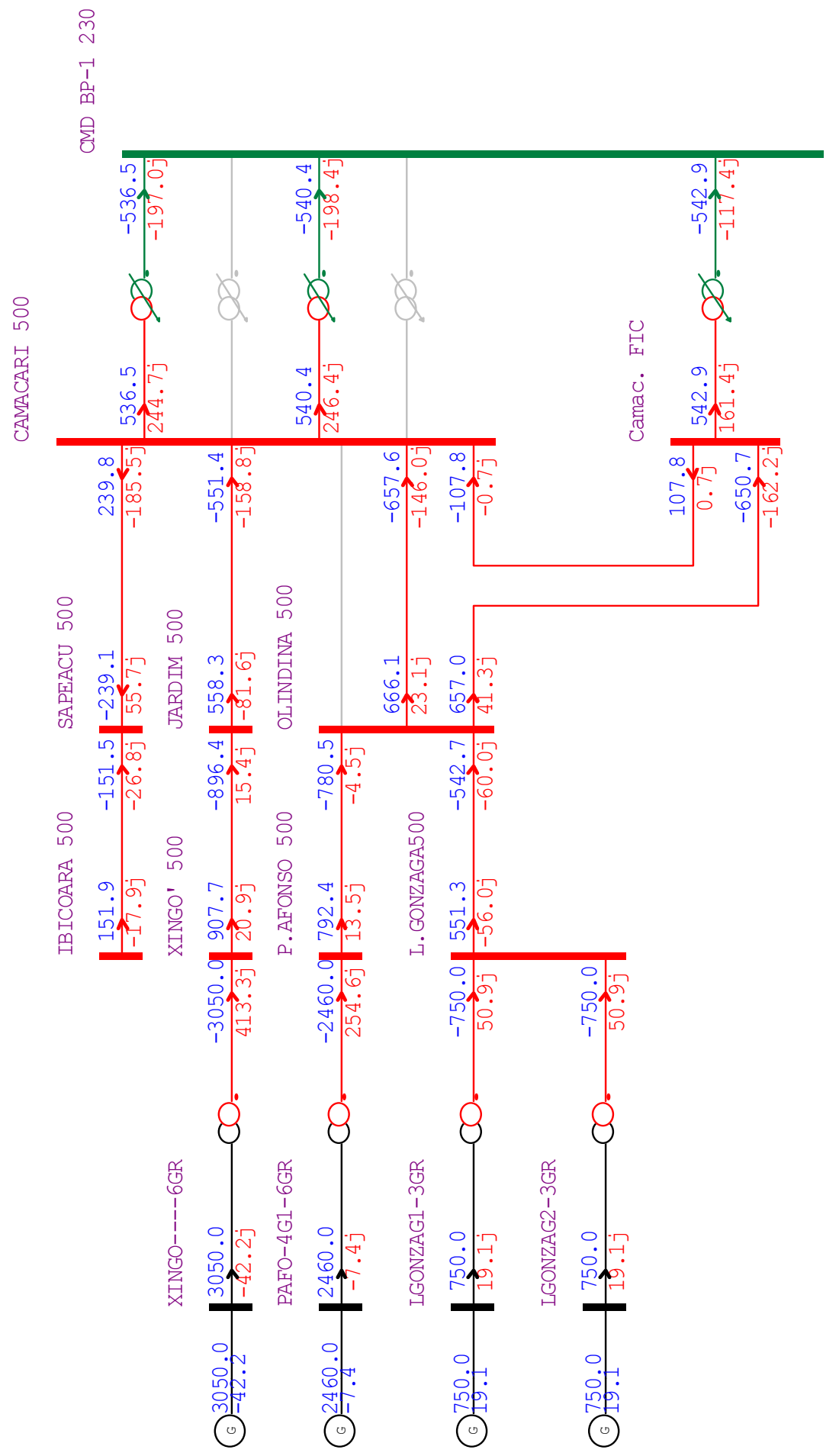


2.4. TEMPO FINAL COM A MODELAGEM DO DISJUNTOR (DJ) (SEÇÃO 4.2.3)

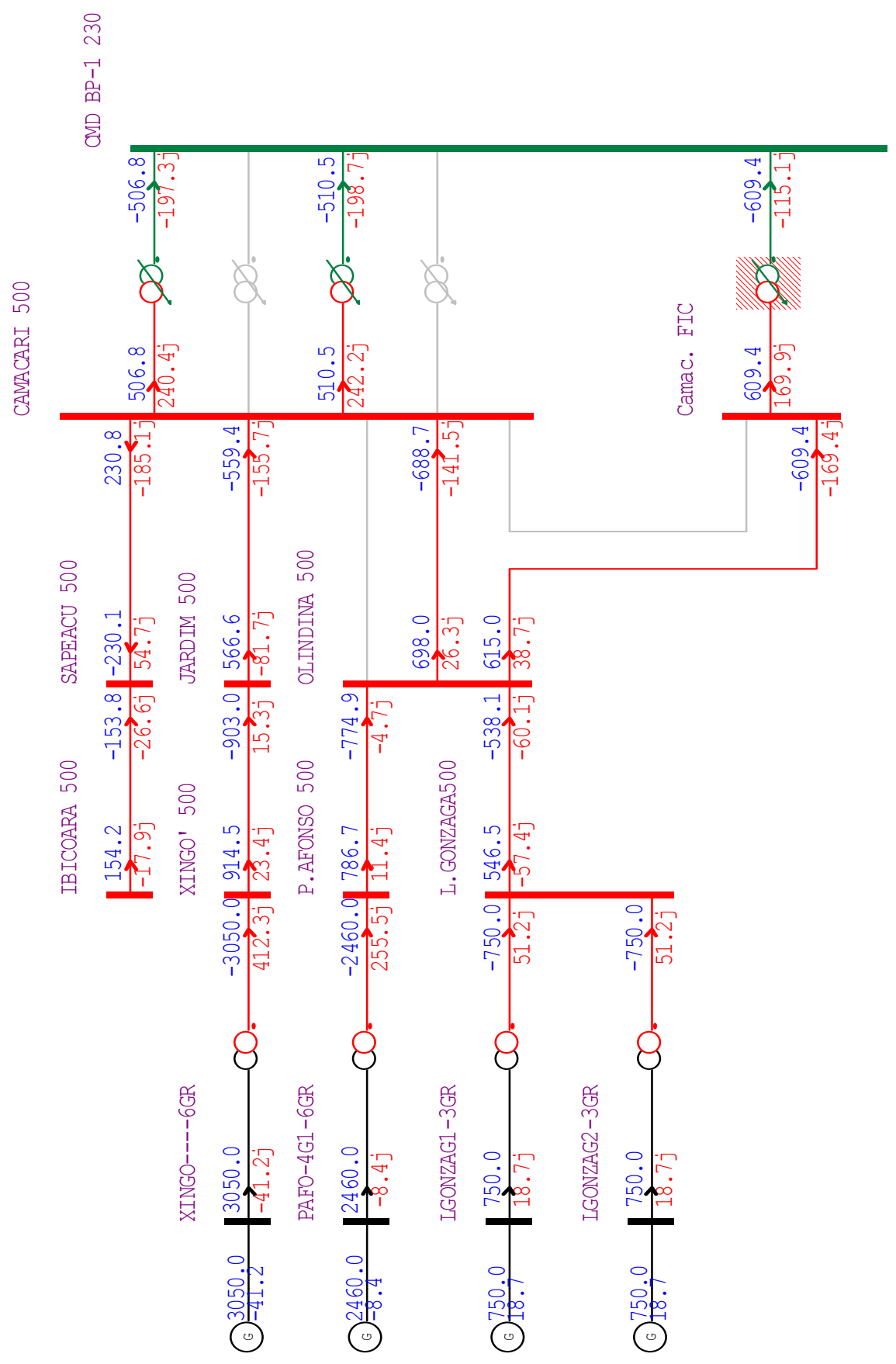

